\title{
微波促进的点击化学
}

\author{
熊兴泉* 蔡 雷唐忠科 \\ (华侨大学材料科学与工程学院 福建省高校功能材料重点实验室＼cjkstart厦门 361021)
}

\begin{abstract}
摘要 自 2001 年 Sharpless 等提出点击化学概念以来, $\mathrm{Cu}(\mathrm{I})$ 催化的炔与叠氮之间的 1,3 -偶极环加成反应 (Cue-AAC) 已经 成为点击化学最成功的范例. Cue-AAC 反应由于其良好的立体选择性、模块性以及官能团耐受性等特点迅速成为许多 研究领域, 例如药物化学、材料科学等领域中的有力工具. 同时, 微波加热作为一种高效、绿色合成技术已越来越受到 人们的重视, 相对于传统加热方式, 它能大幅缩短反应时间, 提高产率和纯度. 综述了近十年来利用微波加热与点击 化学相结合的策略在合成生物大分子及小分子化合物库中的应用, 并对其发展前景作了展望.
\end{abstract}

关键词 点击化学; 微波辅助; 有机合成; 生物大分子; 小分子; 绿色化学

\section{Microwave-Assisted Click Chemistry}

\author{
Xiong, Xingquan* Cai, Lei Tang, Zhongke \\ (Key Laboratory for Functional Materials of Fujian Higher Education, College of Materials Science and Engineering, \\ Huaqiao University, Xiamen 361021)
}

\begin{abstract}
Cu}(\mathrm{I})$-catalyzed azide-alkyne 1,3-dipolar cycloaddition (Cue-AAC), which is the best paradigm of "Click Chemistry" philosophy that was initially coined by Sharpless and co-workers at the very beginning of the third millennium, has been demonstrated as a powerful tool in numerous scientific fields including medicinal chemistry, materials science, etc., due to its superior stereoselectivity, modularity and functional group tolerance. Meanwhile, microwave irradiation has attracted increasingly much attention as a highly effective and green synthetic complement as this technique can distinctly reduce the time consumption and simultaneously enhance the yields and purity of a diverse range of organic reactions in comparison with conventional heating methods. Herein, recent tactics that combine Cue-AAC with microwave irradiation technique toward the construction of useful bio-macromolecules and small molecule libraries are reviewed while the prospective with respect to the future development of this specific area is offered.
\end{abstract}

Keywords click chemistry; microwave-assisted; organic synthesis; bio-macromolecules; small molecules; green chemistry

点击化学概念自 2001 年被 Sharpless 等 ${ }^{[1]}$ 提出, 十 年来已在生物医药、功能材料、表面改性、纳米技术等 领域得到广泛的应用, 成为现代合成方法的典范. 据了 解, 迄今为止与点击反应相关的文献已逾 16000 篇. 一 般而言, 具有以下特点的反应均可被称之为点击反应 ${ }^{[2]}$ : (1)原料来源广, 适用范围广; (2)反应条件温和, 对水和 氧具有耐受性; (3)立体和区域选择性好; (4)产率高, 产 品易纯化; (5) 反应快速, 操作简单. 目前, 在已报道的 点击反应中, 研究最多、应用最广的当属 $\mathrm{Cu}(\mathrm{I})$ 催化的炔 与叠氮之间的 1,3 -偶极环加成反应 ${ }^{[3 \sim 5]}$ (简称 Cue-
$\left.A A C^{[6]}\right)$. 近两年, 国内已有关于 Cue-AAC 反应应用于 环糊精和杯芳烃衍生物合成的综述文章发表 ${ }^{[7,8]}$.

1986 年, Giguere 等 ${ }^{[9]}$ 报道了用微波辅助 4-氧基苯氧 离子与氧苄的 $\mathrm{S}_{\mathrm{N}} 2$ 亲核取代反应可以使反应速率提高 1240 倍, 并且产率也有不同程度的提高. 自此利用微波 辅助加速和控制反应在化学合成领域掀起了一股热潮. 截止到 2011 年下半年, 微波辐射在有机合成领域的文 献已超过 6000 篇, 并仍在持续增长, 关于微波反应的综 述也屡屡见刊 ${ }^{[10 \sim 15]}$. 微波辅助合成大致经历了: 无溶剂 反应 ${ }^{[16 ~ 20]}$, 相转移催化条件 $(\mathrm{PTC})^{[21]}$, 溶剂参与的反

\footnotetext{
*E-mail:xxqluli@hqu.edu.cn

Received October 21, 2011; revised December 18, 2011; published online March 5, 2012.

Project supported by the National Natural Science Foundation of China (No. 21004024), the Natural Science Foundation of Fujian Province (No. 2011J01046), the University Distinguished Young Research Talent Training Program of Fujian Province (No. 11FJPY02) and the Fundamental Research Funds for the Central Universities of China (No. JB-SJ1002).

国家自然科学基金(No. 21004024)、福建省自然科学基金(No. 2011J01046)、福建省 “高校杰出青年科研人才培育计划” (No. 11FJPY02)和中央高校基 本科研业务费(No. JB-SJ1002)资助项目.
} 
应 $^{[22]}$ 和离子液体为溶剂的反应 ${ }^{[23]}$ 等. 微波反应器的不 断改进, 能够控制温度、压强等参数的微波反应器的问 世，为微波反应在合成领域的不断推广创造了条件.

事实上, 微波加热是一种分子内加热, 被加热的底 物分子内部不存在温度梯度, 因此与传统的加热方式相 比, 微波加热具有极高的效率. 2004 年, Kappe 等 ${ }^{[24]}$ 最早 发现, 利用微波来促进点击反应, 可以大幅提高点击反 应的效率、缩短反应时间及减少副产物的产生. 鉴于这 方面的研究发展迅速, 目前国内又尚无这一领域的综述 报道, 因此对这一领域的发展动态进行较为全面的介绍 十分必要. 基于上述原因, 本文就近几年来微波辅助在 点击化学中的应用作一综述.

\section{1 生物大分子}

\section{1 肽及肽类似物}

叠氮基与炔基之间的 Cue-AAC 反应能生成稳定的 三唑环衍生物, 因此 Cue-AAC 化学被广泛用作各种分 子之间连接反应. 除此之外, 由于三唑环的电子效应与 肽键相似, 被用于合成氨基酸及肽类似物. 肽类似物具 有类似肽的功能, 但是不含有易水解的酰胺键, 故其具 有很大的应用潜力 $\left.{ }^{[25 ~} 29\right]$. Angelo 等 ${ }^{[30]}$ 通过 “一锅两步” 法合成了基于三唑环的肽类似物, 整个反应过程是氨基 酸甲酯在金属催化作用下室温搅拌 $1.5 \mathrm{~h}$, 发生重氮转 移反应生成叠氮衍生物 ${ }^{[31,32]}$. 然后它与 $N$-Boc-氨基-炔 化合物在微波辅助下发生 Cue-AAC 反应 ${ }^{[33,34]}\left(80{ }^{\circ} \mathrm{C}, 5\right.$ $\min$ ), 产率大于 $90 \%$. 在去 Boc 保护以后, 重复上述步 骤能制备出链增长的肽类似物(Eq. 1).

最近, Andrade 等 ${ }^{[35]}$ 利用微波辅助 Ugi 反应合成一 系列包括叠氮和炔基功能化的的肽类似物, 再通过微波 辅助 Cue-AAC 反应可以使肽类似物发生交联(Eq. 3), Cue-AAC 反应仅耗时 $1 \mathrm{~min}$, 产率即达 73\%, 而若在室

$$
\text { triazolamer }
$$

温下反应 $18 \mathrm{~h}$, 产率只有 $63 \%$.

Cecioni 等 ${ }^{[36]}$ 将合成的炔基功能化的线性及环形肽 类似物、杯 [4]芳烃、卟啉及杯[6]芳烃作为核心, 分别与 叠氮化的糖在微波作用下合成了四元和六元糖簇物, 他 们通过 HIA, SPR 和 ITC 对上述多元糖簇物与两种植物 凝血素(ECA 和 PA-IL)之间的结合作用, 发现六元糖簇 物的结合能力最强. 研究表明, 这些糖簇物可作为抗感 染药物特别是在抵抗绿脓杆菌感染方面具有独特功效.

Perissutti 等 ${ }^{[3]}$ 利用炔酰胺与 Fmoc 保护的氨基-叠 氮化合物在 $\mathrm{Cu}(\mathrm{I})$ 催化剂作用下进行微波辅助的 Cue-AAC 反应. 该反应在无溶剂的条件下进行, 将催化 剂与原料分散在碱性氧化铝中, 微波辐射 $20 \mathrm{~min}$ 后, 经 硅胶色谱柱分离得到含有三唑环的肽模拟物产率为 $26 \% \sim 71 \%$ (Eq. 3).

基于肽的聚合物可以作为给药体系、组织工程与修 复支架以及新型生物材料. Cue-AAC 反应近来也被有效 地应用于肽聚合物的合成, Liskamp 小组 ${ }^{[38]}$ 将二肽衍生 物 $\mathrm{N}_{3}$-Phe-Ala-炔丙基酰胺在不同的条件下经过微波辅 助的 Cue-AAC 反应制备了线型及环型的肽聚合物. 两 者的氨基酸残基数量分别达到 300 个和 $4 \sim 20$ 个 (Scheme 1).

2008 年, 该课题组又报道了利用相同的方法, 采用 $\mathrm{N}_{3}$-Phe-Ala-Lys-炔丙基酰胺和 $\mathrm{N}_{3}$-Phe-Ala-Glyc-Lys-炔 丙基酰胺作为三肽和四肽单体(Scheme 2)合成了具有<smiles>C#CCN(CC(=O)NCC(=O)OC)C(=O)CNC(=O)OCc1ccccc1COC(=O)COCCOC(=O)NCC(=O)N(CCCCN)CC(=O)NCC(=O)OCc1ccccc1</smiles><smiles>COC(=O)CNC(=O)CN(CCCn1cc(CN(CC(=O)NCC(=O)OC)C(=O)CNC(=O)OCc2ccccc2)nn1)C(=O)CNC(=O)OCc1ccccc1</smiles> 

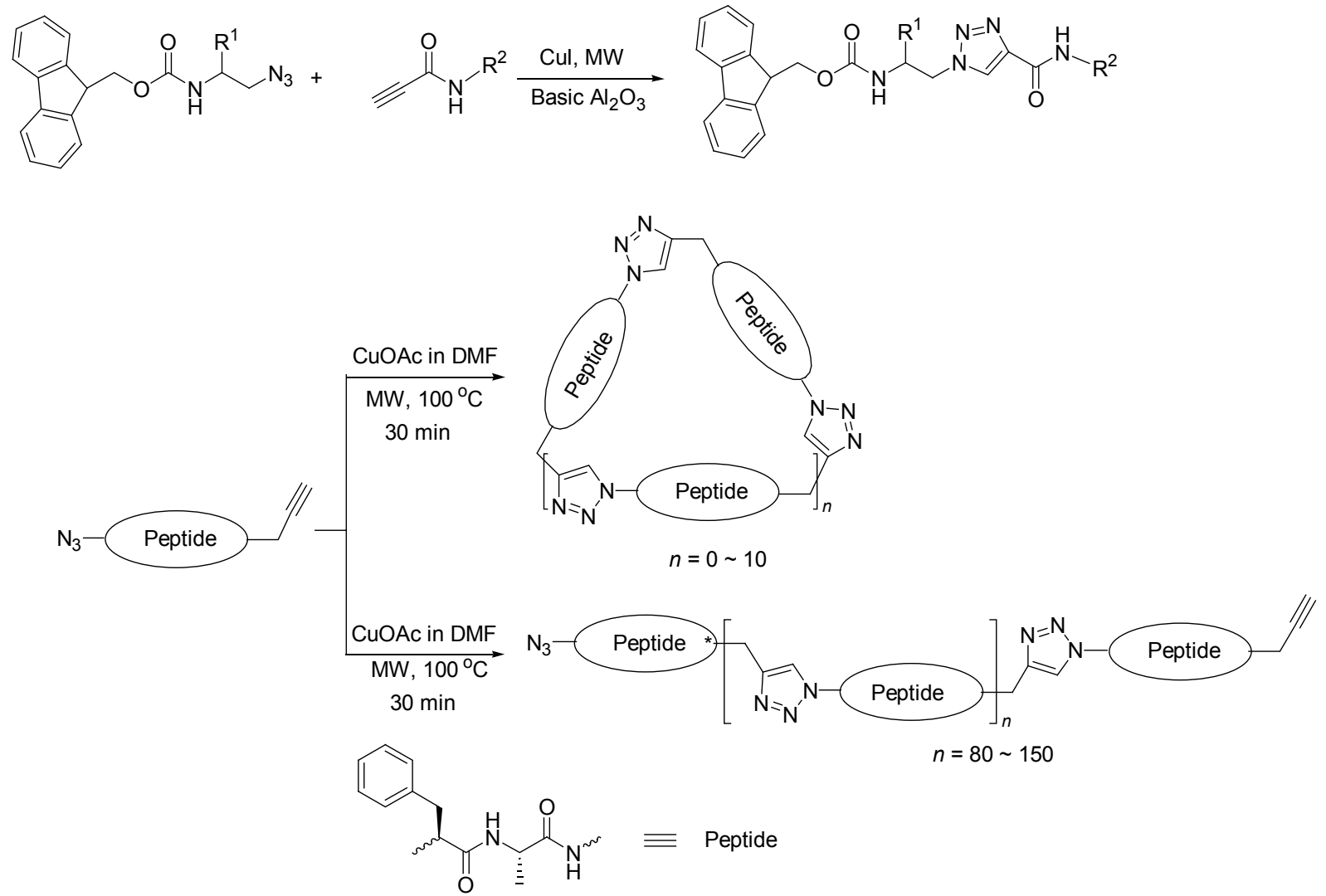

Scheme 1

$33 \sim 100$ 个氨基酸残基的聚合物链 ${ }^{[39]}$. 这两种单体中存 在酶降解或化学水解活性位点, 故以它们为单体制备出 的基于三唑环的聚合物具有可生物降解的性质.<smiles>C#CCNC(=O)[C@H](CCCN)NC(=O)COC(=O)[C@H](C)NC(=O)[C@H](N)Cc1ccccc1</smiles>

Scheme 2

随后，该课题组报道合成了淀粉样肽序列为重复单 元的环形寡聚物 ${ }^{[40]}$, 用以获得新型自组装生物纳米材 料. 具体是以 $\mathrm{N}_{3}$-Lys-Leu-Val-Phe-Phe-Ala-Glu-炔丙基 酰胺为单体, 将其溶解在 $\mathrm{N}_{2}$ 除氧的 DMSO 中, 再加入 $\mathrm{CuOAc}$, 将混合物置于微波反应器中, $100{ }^{\circ} \mathrm{C}$ 下辐射 30 min. 在过程中, 单体和二聚体通过 HPLC 分离, 采用
MALDI-TOF 分析寡聚物的聚合度(Eq. 4, 3 和 4).

\section{2 树状化多肽及其类似物}

微波辅助 Cue-AAC 反应不仅可被应用于合成线型多 聚肽、肽模拟物, 而且还能用于树状化多肽的合成 ${ }^{[41 \sim 43]}$. Liskamp 等由 3,5-二羟基苯甲酸出发制备了 G1, G2, G3, G4 的炔基功能化树状多肽中间体，然后在催化剂 $\mathrm{CuSO}_{4} / \mathrm{NaAsc}(\mathrm{Asc}=$ ascorbate $)$ 作用下与合适的叠氮一酸 及叠氮一氨基酸进行微波辅助 $\left(100{ }^{\circ} \mathrm{C}\right)$ 的 Cue-AAC 反应. 结果表明, 微波辅助 Cue-AAC 反应能够明显缩短反应 时间和提高产率(10 min, 最高达 93\%) (Scheme 3).

该课题组采用相同的手段合成了接有放射性示踪 物 1,4,7,10-四氮杂癸烷- $N^{1}, N^{4}, N^{7}, N^{10}$-四乙酸(DOTA)的环 形-RGD(Arg-Gly-Asp 三肽)树状分子 ${ }^{[44]}$ (Scheme 4). 该 反应是叠氮功能化的 $\mathrm{cRGD}$ 与炔功能化树状分子在 $\mathrm{Cu}(\mathrm{I})$ 催化剂存在下， $100{ }^{\circ} \mathrm{C}$ 微波辐射 $10 \sim 30 \mathrm{~min}$ 完成 的, 产率为 $57 \%$. 结果表明, 树状化 DOTA-cRGD 相比 其一元形式对癌细胞的标记能力大大提高.

另外，该课题组还用相同的方法将叠氮功能化的磷 肽键合到一元、二元、四元及八元的炔功能化树状分子 上, $80{ }^{\circ} \mathrm{C}$ 微波加热 $20 \mathrm{~min}$ 后, 经 RP-HPLC 分离产率分别 可达 $94 \%, 53 \%, 50 \%, 56 \%{ }^{[45]}$. 通过微波辅助 Cue-AAC 反 应可对含有精氨酸残基的多肽进行标记 ${ }^{[46]}$ (Eq. 5). 


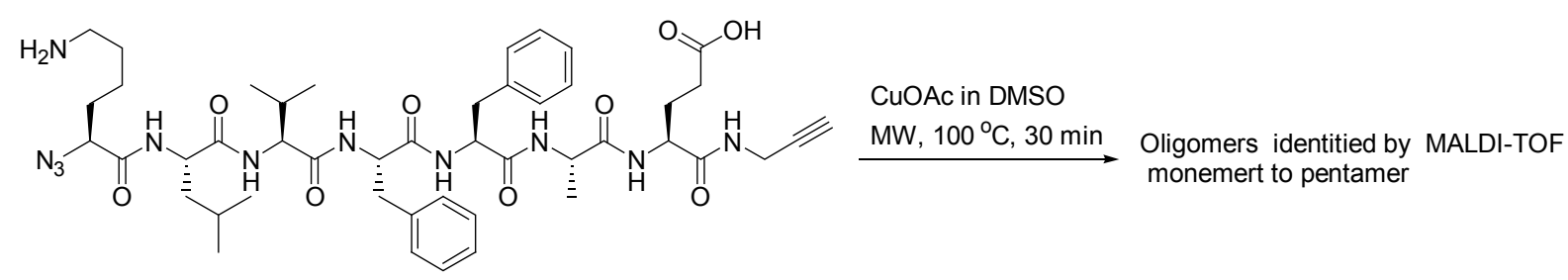

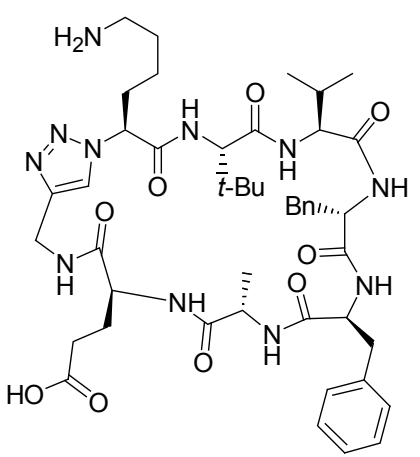

3
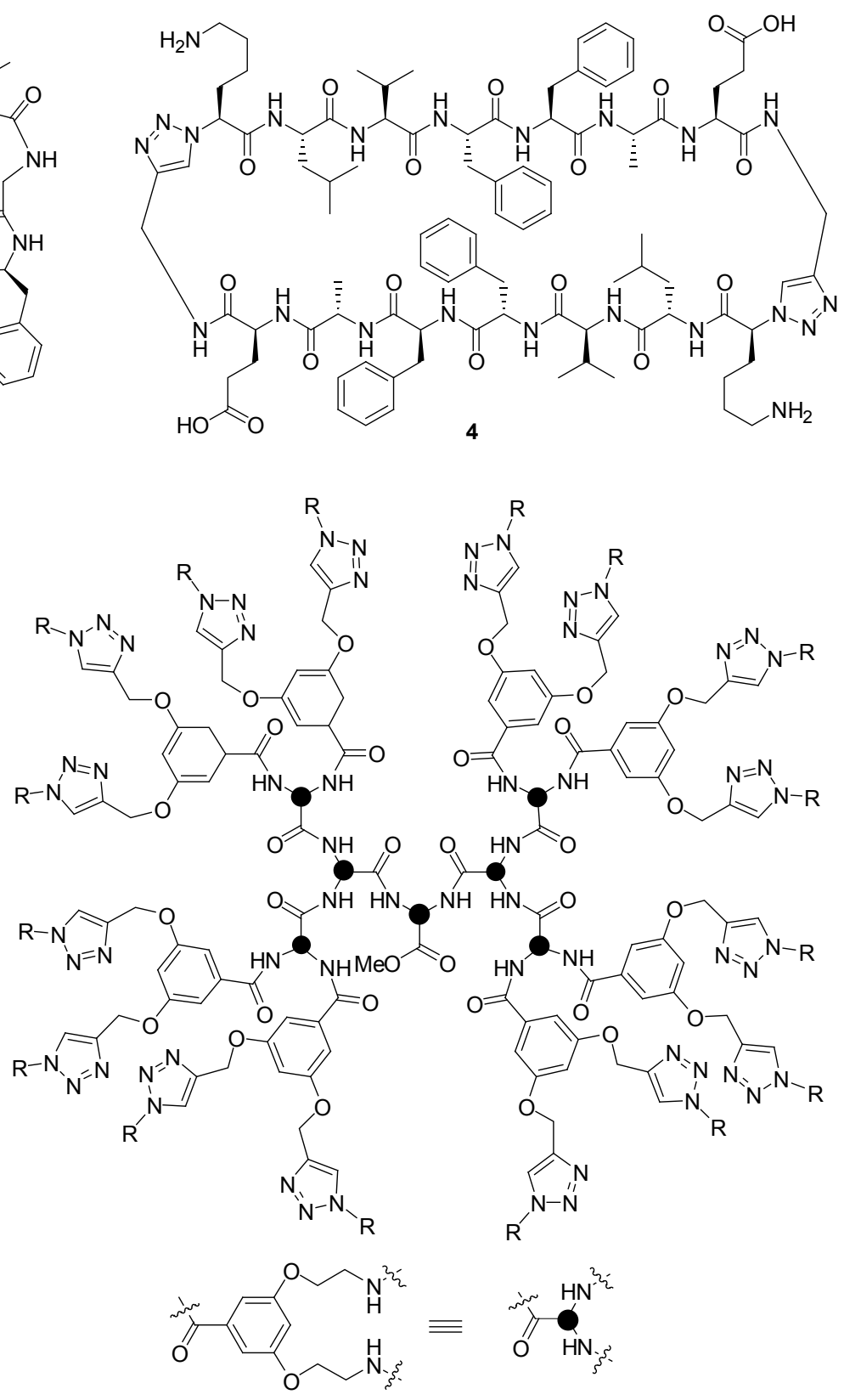

Scheme 3

Weck 等 ${ }^{[47]}$ 设计并合成了单叠氮或单炔基功能化聚 酰胺树状分子, 并利用 Cue-AAC 反应对该官能团进行 有针对性的改性 (Scheme 5). Cue-AAC 反应, 以 $t$ - $\mathrm{BuOH} / \mathrm{H}_{2} \mathrm{O}$ 为溶剂, $5 \mathrm{~mol} \% \mathrm{CuSO}_{4} / 10 \mathrm{~mol} \% \mathrm{NaAsc}$ 作 催化剂, $100{ }^{\circ} \mathrm{C}$ 微波加热 $10 \mathrm{~min}$, 反应产率 95\% 98\%. 两种单功能化的树状分子的 Cue-AAC 反应活性没有明
显差别. 而若在常规加热条件进行该反应, $80{ }^{\circ} \mathrm{C}$ 加热反 应需要 $20 \mathrm{~h}$ 产率才达到 $97 \%$.

Arnusch 等 ${ }^{[48]}$ 用标准固相肽合成法分别制备了叠氮 功能化的成孔抗菌肽 magainin 2, 将其与炔功能化的树 状分子在 $\mathrm{DMF} / \mathrm{H}_{2} \mathrm{O}$ 溶剂中混合, 以 $\mathrm{CuSO}_{4} / \mathrm{NaAsc}$ 作为 催化剂, $80{ }^{\circ} \mathrm{C}$ 微波加热 $20 \mathrm{~min}$, 可得到肽树状分子. 值 


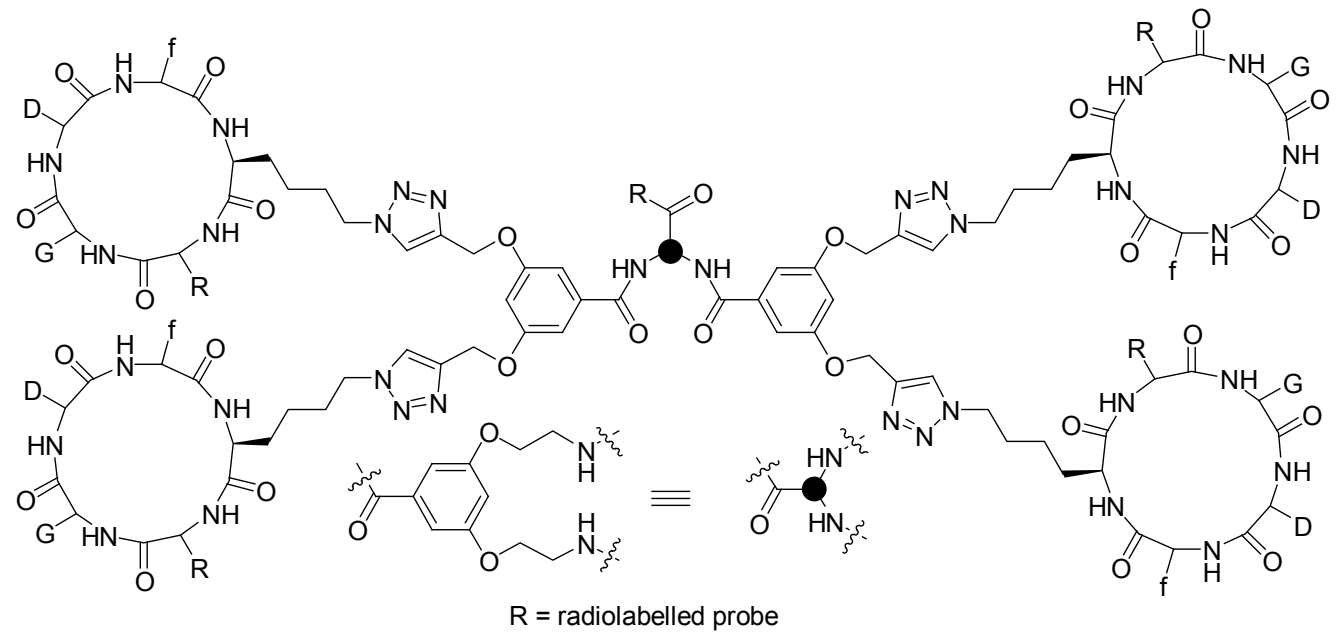

Scheme 4

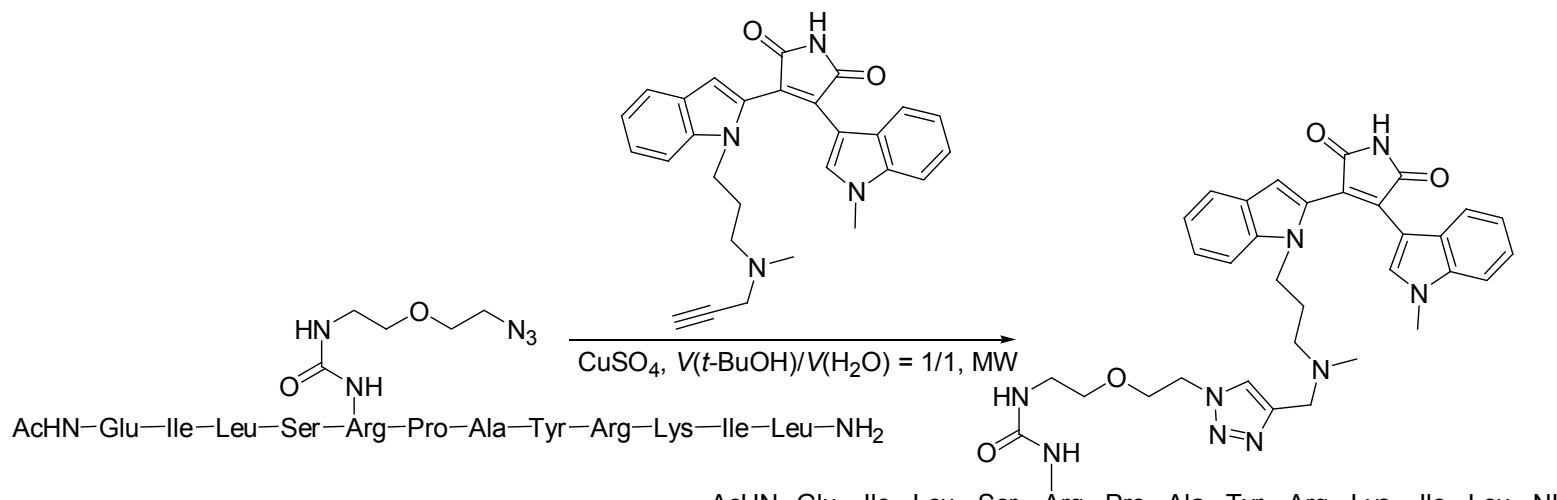

AcHN-Glu-Ile-Leu-Ser-Arg-Pro-Ala-Tyr-Arg-Lys-Ile-Leu-NH

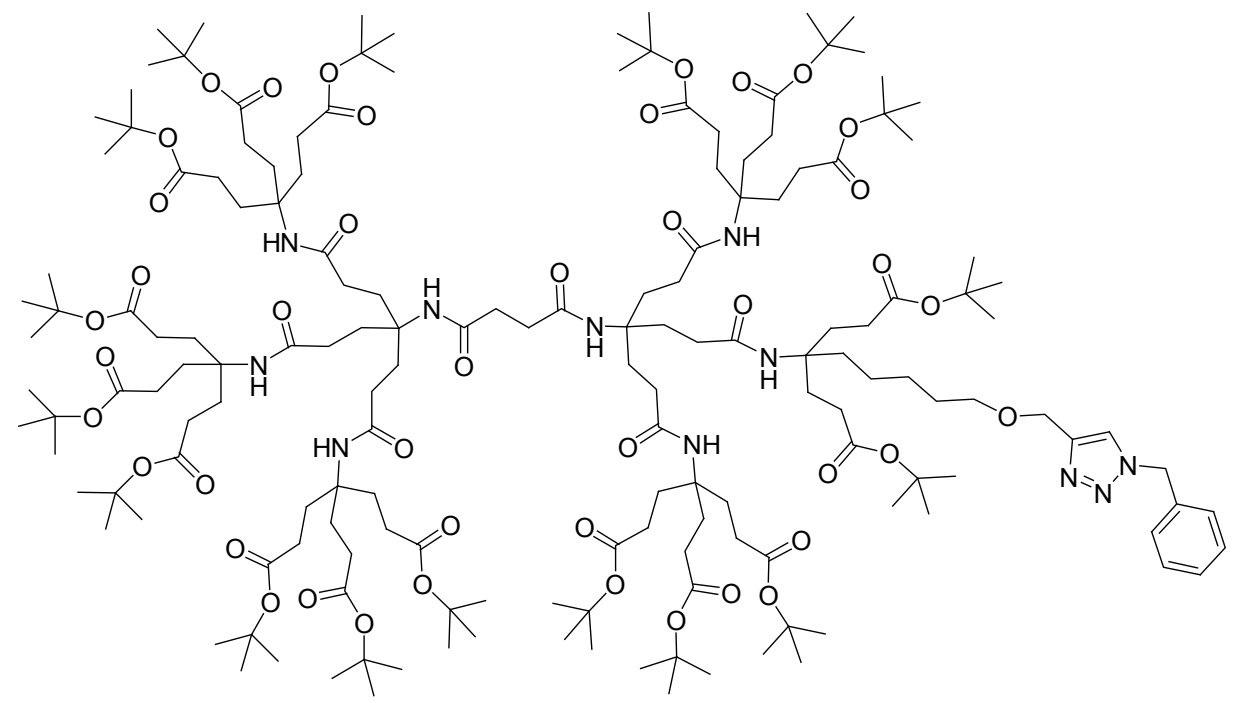

Scheme 5

得一提的是, 反应时需投入过量的叠氮功能化 magainin 2, 以保证反应能够进行完全.

\section{3 糖缀物、寡糖及多糖}

\subsection{1 糖肽及其类似物}

由于 $2(1 H)$-吡嗪酮的六元环体系是一种合成肽类似
物的优良前体, Van der Eycken 等 ${ }^{[49]}$ 曾报道了利用微波 辐射，过渡金属催化的反应对 2(1H)-吡嗪酮支架的修饰. 并希望能通过 2(1H)-吡嗪酮支架与不同的糖类衍生物之 间的反应合成肽类似物 ${ }^{[50]}$.

他们将炔基化的吡嗪酮与叠氮化的单糖和二糖作 
为原料, $\mathrm{CuSO}_{4} / \mathrm{Cu} / \mathrm{TBTA}$ 作为催化体系, 在 $\mathrm{THF} / \mathrm{H}_{2} \mathrm{O}$ $(V: V=1: 1)$ 混合溶剂中进行微波辐射 $\left(100 \mathrm{~W}, 85{ }^{\circ} \mathrm{C}\right.$, $10 \sim 12 \mathrm{~min}$ ), 产率达到 $90 \%$ 以上 $^{[51]}$ (Eq. 6).

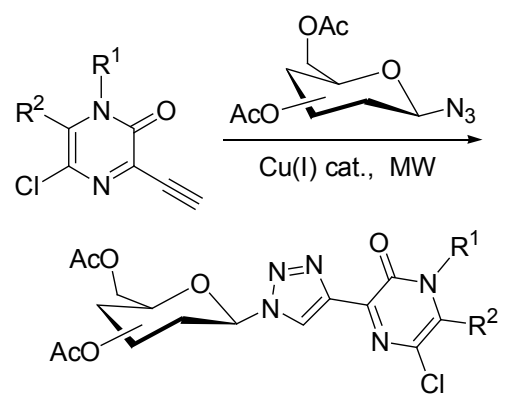

糖基化氨基酸作为糖肽固相合成的砌块，可利用烷 基链或三唑环实现糖与氨基酸的结合. Ziegler 等 ${ }^{[52]}$ 于 2008 年合成了同时具有叠氮基、炔基的吡喃糖, 并使其 在 $(\mathrm{EtO})_{3} \mathrm{P} / \mathrm{CuI}$ 作催化剂的条件下与炔基化的天门冬氨 酸 $^{[53]}$ 反应, 产率为 $61 \%$. 他们还发现该双功能化的吡喃 糖在 $(\mathrm{EtO})_{3} \mathrm{P} / \mathrm{CuI}$ 催化剂存在下, 不论有或无微波辅助的 情况下能发生自身反应，生成环形二糖(14\% 54\%). 当 吡喃糖的保护基为苄基时, 则只会生成线性的寡糖类似 物(Eq. 7, 5 和 6). 结果表明, 微波虽然能大幅缩短反应 时间, 但却可能造成原料的分解.
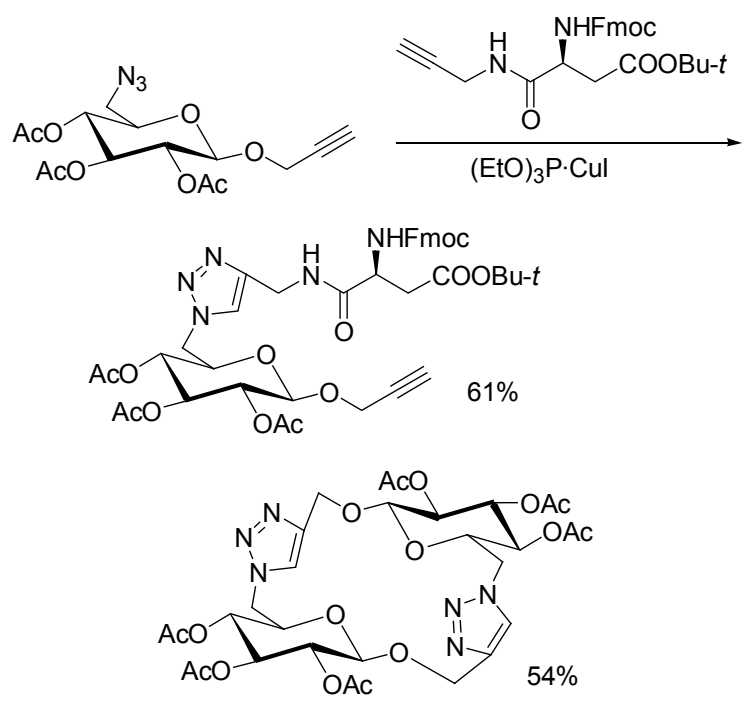

5

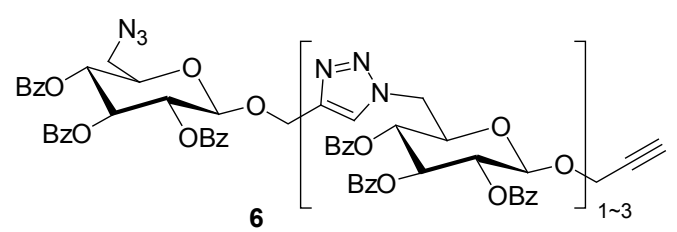

高等真核生物细胞中有一种 $\alpha-N$-乙酰化半乳糖胺 与丝氨酸或苏氨酸着基结合的糖肽链, 被称为 $\mathrm{Tn}$-抗原. 抗冻糖肽(AFGPs)中也普遍存在与此类似的结构. Miller
等 ${ }^{[54]}$ 用 Fmoc-SPPS 法合成了叠氮功能化的肽链, 并使 其与炔基功能化的 $\alpha$-GalNAc 在 $\mathrm{H}_{2} \mathrm{O} / t-\mathrm{BuOH}$ 混合溶剂 中进行微波辅助 $\left(80{ }^{\circ} \mathrm{C}\right)$ 的 Cue-AAC 反应(Eq. 8). 通过 一系列对比实验可知最优的催化剂体系为 $5 \mathrm{~mol} \%$ $\mathrm{Cu}(\mathrm{OAc})_{2}$ 和 $15 \mathrm{~mol} \% \mathrm{NaAsc}$, 反应在 $5 \mathrm{~min}$ 以内即可 $100 \%$ 转化, 产率达 $87 \%$.

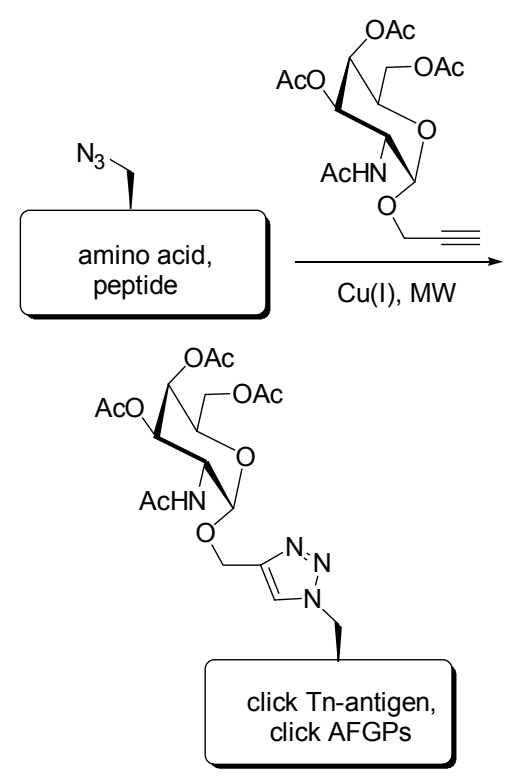

Ben 等 ${ }^{[55]}$ 最近也报道了含有三唑环结构的 AFGP 和 c-AFGP 类似物的合成方法. 先用收敛的固相合成法 得到了炔功能化的肽链, 再与叠氮功能化的糖发生点击 反应. 反应条件为 $\left(\mathrm{MW}, 45 \mathrm{~W}, 90{ }^{\circ} \mathrm{C}\right.$, 无水 $\mathrm{DMF}$, $\mathrm{CuSO}_{4} / \mathrm{NaAsc}$ ), 产率 $16 \% \sim 54 \%$.

\subsubsection{DNA 糖簇物}

微波辅助 Cue-AAC 反应同样可以应用到基于 DNA 的糖簇物的固相合成方面. Vidal 等 ${ }^{[56]}$ 先合成了双炔基 功能化的季戊四醇磷酸二酯(PePOs) 寡聚物, 接着再将 其与叠氮化的岩藻糖在微波辅助下 $\left(100 \mathrm{~W}, 60{ }^{\circ} \mathrm{C}, 30\right.$ $\min$ )发生点击反应. 得到分别含有 $4,6,8,10$ 个岩藻糖 残基的糖簇物. 类似工作随后被 Pourceau 等 ${ }^{[57]}$ 报道, 所 不同的是他们选用的是叠氮化的半乳糖作为糖基供体.

微波辅助 Cue-AAC 反应还能用于叠氮化的半乳糖 与炔基功能化的塞核苷酸的结合，反应能用固相合成或 在溶液中进行 $\left(\mathrm{MW}, 60{ }^{\circ} \mathrm{C}, 20 \mathrm{~min}\right)^{[58]}$.

\subsection{3 基于杯芳烃的生物分子}

Bew 等 ${ }^{[59]}$ 于 2007 年报道了在杯 [4]芳烃上缘通过微 波辅助 Cue-AAC 反应连接上氨基酸、二肽、糖类等生 物活性分子. 他们将四叠氮化和 1,3-二叠氮化的杯 [4]芳 烃与炔功能化的生物活性分子在 $\mathrm{CuSO}_{4} / \mathrm{NaAsc}$ 作催化 剂的条件下进行微波辐射，产率分别可达 $40 \%$ ～ $89 \%$ 和 $23 \% \sim 50 \%$. 
离子液体被认为是一种绿色溶剂, 由于其极性较 高, 能有效吸收微波, 故广泛用于微波合成领域 ${ }^{[60 ~ 63]}$. Dondoni 等 ${ }^{[64]}$ 用四叠氮化的杯 [4]芳烃与炔功能化的 $C$ 半乳糖苷分别在三种不同离子液体中有 $\mathrm{CuI} / i-\mathrm{Pr}_{2} \mathrm{EtN}$ 存 在条件下施以微波辐射 $\left(80{ }^{\circ} \mathrm{C}, 2 \mathrm{~h}\right)$, 合成了三唑环链接 的四- $C$-半乳糖基-杯 [4]芳烃族合物, 产率最高可达 $90 \%$ (Eq. 9), 而采用传统的加热方式需耗时 $16 \mathrm{~h}$, 产率也相 对较低。

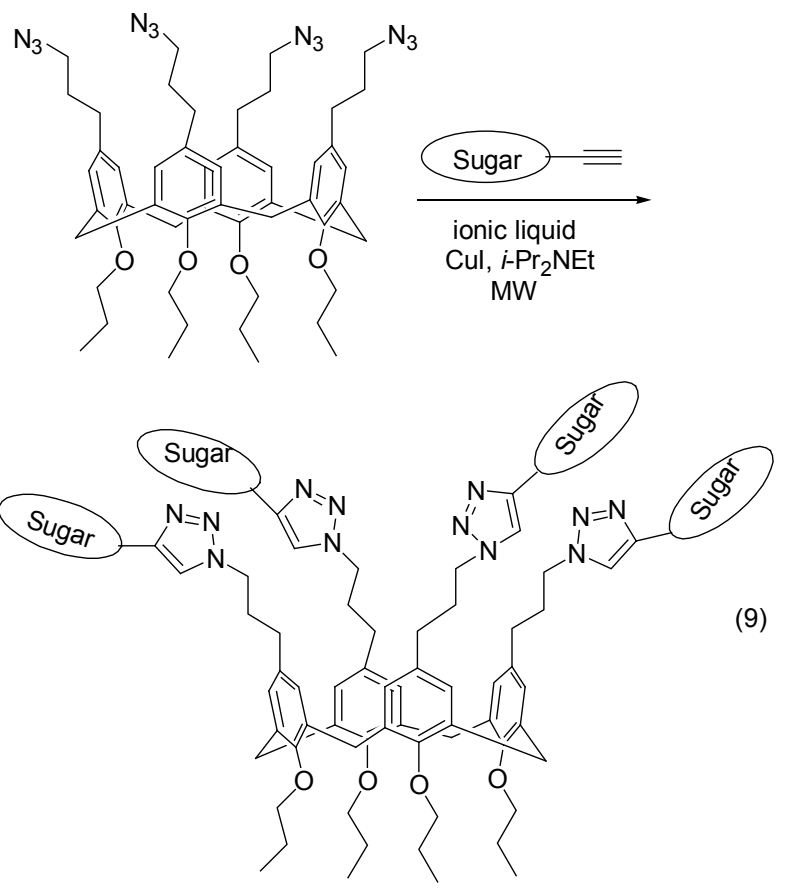

Cecioni 等 ${ }^{[65]}$ 采用不同的条件合成了一系列炔功能化 的杯[4]芳烃衍生物, 包括一、二、三、四取代及构象异 构体. 再在 CUI/DIPEA 作催化剂条件下, $110{ }^{\circ} \mathrm{C}$ 微波辅助 Cue-AAC 反应可高产率得到相应的杯芳烃-糖缀物. 以 簇合物形式存在的糖缀物相比单取代形式的具有更强的 针对 PA-IL 凝集素的亲和力. 另外, 杯芳烃-糖缀物三维 构象的不同也会影响其与蛋白质表面的亲和作用.

Ritter 等 ${ }^{[66]}$ 报道了杯 [4]芳烃与环糊精通过微波辅助 Cue-AAC 反应实现连接, 并考察了其与带有金刚烷残 基的共聚物之间的超分子作用. 当体系所处环境的 $\mathrm{pH}$ 值升高, 杯 [4]芳烃部分的羟基去质子化后, 共聚物的溶
解度及流体力学半径发生显著变化, 说明金刚烷残基与 环糊精之间发生了超分子作用.

Consoli 等 ${ }^{[67]}$ 最近报道了利用微波辅助 Cue-AAC 反 应将叶酸分子接枝到杯芳烃上. 反应以 $\mathrm{CuSO}_{4} / \mathrm{NaAsc}$ 为 催化剂, DMSO 为溶剂, $70{ }^{\circ} \mathrm{C}$ 微波辐射 $30 \mathrm{~min}$, 产率为 $40 \%$. 他们还考察了该叶酸一杯芳烃缀合物对疏水性消 炎药茚甲新的运载能力, 发现随着缀合物浓度的升高, 狮甲新在磷酸缓冲溶液中的溶解度呈线性上升. 叶酸与 其受体的特异性结合提高了药物的细胞摄入量, 有助于 该缀合物作为一种靶向药物控释载体在生命科学中的 应用. 类似地，还可以将造影剂及其它药物分子以共价 键或非共价键的形式与杯芳烃结合，扩大该类缀合物的 应用范围。

\subsection{4 糖树状分子}

以炔基功能树状分子作为核也可与叠氮功能化的 糖发生点击反应生成糖树状分子 ${ }^{[68]}$, 这也是糖簇合物的 一种. 点击反应在 $\mathrm{DMF} / \mathrm{H}_{2} \mathrm{O}$ 混合溶剂中进行, $\mathrm{CuSO}_{4} /$ $\mathrm{NaAsc}$ 作催化剂. 若该体系在室温下反应，则要求过夜， 转化率和产率都较低. 当使用微波辅助 $\left(80{ }^{\circ} \mathrm{C}, 20\right.$ $\mathrm{min}$ ), 产率得到 $95 \%$ 以上(Eq. 10). 另外, 还合成了两个 带有 NBD-苂光标记的糖树状分子，具有十分重要的生 物学价值.

$\left(\mathrm{Ph}_{3} \mathrm{P}\right)_{3} \cdot \mathrm{CuBr}$ 和 $(\mathrm{EtO})_{3} \mathrm{P} \cdot \mathrm{CuI}$ 是两种可以溶于有机溶 剂的 $\mathrm{Cu}(\mathrm{I})$ 催化剂，比较容易制备，且在空气中稳定，用 它们在微波辅助下催化 $N-, O-, S$-炔丙基- $\beta$ - $D$-甘露糖苷与 单、双、多叠氮取代核之间的 Cue-AAC 反应，产率最高 可达 $99 \%$ (Eq. 11). 而反应在常温下进行, 通常需要数 小时或数十小时 ${ }^{[69]}$.

\subsection{5 环糊精 $(\mathrm{CD})$ 衍生物}

Delattre 等 ${ }^{[70]}$ 将合成了三脚架型的全乙酰化的 CD 三聚体. 他们是用单叠氮取代的全乙酰化 $\mathrm{CD}^{[71]}$ 与 $1,3,5-$ 三炔丙氧基苯 ${ }^{[72,73]}$ 在 DMSO 中以 CuI/DIPEA 催化剂进 行微波辅助 $\left(210 \mathrm{~W}, 80^{\circ} \mathrm{C}, 1 \mathrm{~h}\right)$ 的 Cue-AAC 反应. 反应 完以后, 将混合物冷却至室温, 并溶于 $\mathrm{CH}_{2} \mathrm{Cl}_{2}$, 用 EDTA 将 $\mathrm{Cu}$ 以 $\mathrm{Cu}(\mathrm{II})$ 络合物的形式除去.

Cravotto 等 ${ }^{[74]}$ 运用微波辅助 Cue-AAC 反应合成了 双聚、三聚 $\mathrm{CD}$ 化合物库. 他们早先报道了单或双叠氮

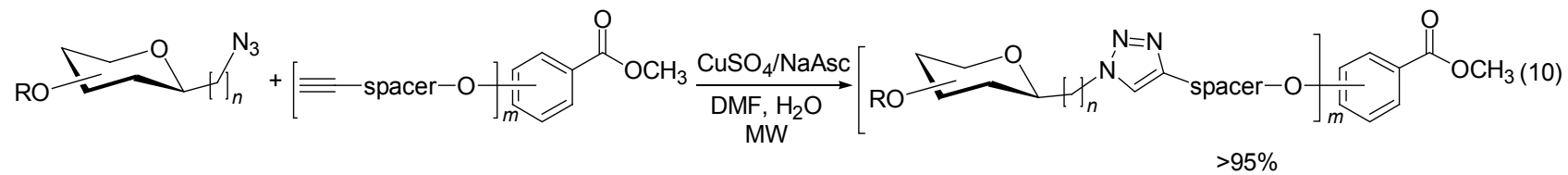

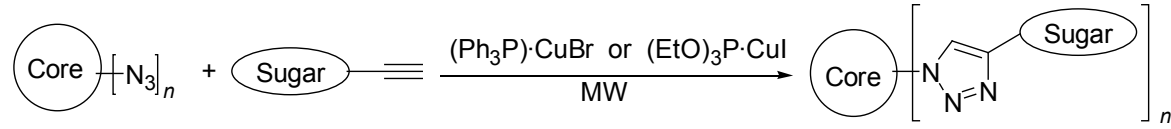


功能化 $\mathrm{CD}$ 和炔基化 $\mathrm{CD}$, 令其在 $\mathrm{CuSO}_{4} / \mathrm{NaAsc}$ 催化作 用下生成了双聚和三聚体 $\mathrm{CD}$. 后来他们又报道了类似 方法合成了经二叠氮或二炔取代的芳香衍生物连接的 双聚和三聚体 $\mathrm{CD}^{[75]}$, 丰富了该化合物库. 研究表明, 这 些化合物中, $\mathrm{CD}$ 的连接位置及 $\mathrm{CD}$ 空穴尺寸的各异性, 有利于调节 $\mathrm{CD}$ 与客体分子(如药物分子)之间的相互作 用.

$\mathrm{Gd}^{3+}$ 常应用于磁共振成像技术(MRI), 增强图像的 对比度. Meade 等 ${ }^{[76]}$ 采用常规和微波加热两种方式合成 了含有 $\mathrm{Gd}^{3+}$ 的环糊精衍生物, 它能用于 MRI, 效果优于 现有的 $\mathrm{Gd}^{3+}$ 复合物.

Tran 等 ${ }^{[77]}$ 合成了基于 $\mathrm{CD}$ 的手性单极和二极受体分 子. 他们以炔基化的手性氨基酸与 $\mathrm{N}_{3}-\beta$ - $\mathrm{CD}$ 为反应原料, 以 $\mathrm{CuSO}_{4} / \mathrm{NaAsc}$ 作催化剂, 先在室温条件下合成了单极 氨基酸- $\mathrm{CD}$ 化合物, 用时 $18 \mathrm{~h}$, 反应物定量转化. 微波 辅助 $\left(60{ }^{\circ} \mathrm{C}\right)$ 合成二极氨基酸- $\mathrm{CD}$ 时, 反应物达到定量转 化仅需 $2 \mathrm{~h}$, 其传统方法室温搅拌 $24 \mathrm{~h}$, 产率仅为 $10 \%$ $34 \%$ 相比，具有明显的优势(Eq. 12).
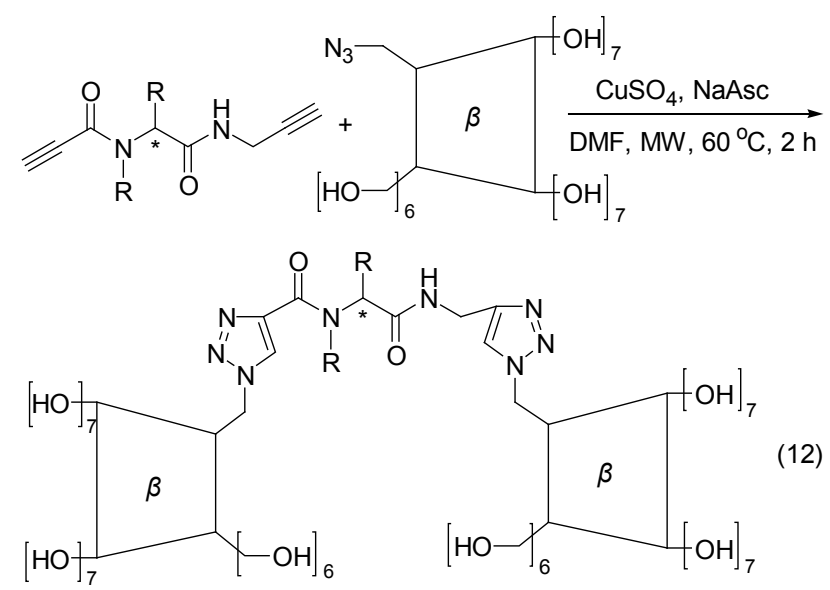

Hoogenboom 等 ${ }^{[78]}$ 利用七取代 $\mathrm{N}_{3}$ - $\mathrm{CD}$ 与炔基功能化 的的聚合物链 (p\&CL) 在 $\mathrm{DMF}$ 中发生微波辅助的 Cue-AAC 反应 $\left(100{ }^{\circ} \mathrm{C}, 15 \mathrm{~min}\right)$, 生成了具有七臂的星 形聚合物. 类似地, 2008 年 Fijten 等 ${ }^{[79]}$ 也报道了采用微 波辅助的点击化学合成了基于环糊精的七臂星形聚合物.

Ortega-Munoz 等 ${ }^{[80}$ 报道合成了荧光和无荧光的糖 聚物 7、糖基 $\mathrm{CD}$ 、糖簇物 8 (Scheme 6). 聚对叠氮甲基 苯乙烯是由对氯甲基苯乙烯在 DMF 中合成的 ${ }^{[81]}$, 令其 与炔基功能化的半乳糖、乳糖和苂光物质 $\mathrm{Fph}$ 进行 Cue-AAC 反应 $\left[(\mathrm{EtO})_{3} \mathrm{P} / \mathrm{CuI}, \mathrm{DMF}, \mathrm{MW}, 800 \mathrm{~W}, 90{ }^{\circ} \mathrm{C}\right.$, $15 \mathrm{~min}]$. 以全乙酰化的单叠氮和七叠氮功能化的 $\beta-\mathrm{CD}^{[82]}$ 为原料代替聚对叠氮甲基苯乙烯, 其余的反应 试剂和条件均保持不变, 可快速合成糖基 $\mathrm{CD}$. 他们还 在甲苯中回流 $1 \mathrm{~h}$ 合成了糖簇物. 为了保证生成 $100 \%$ 转 化的新型糖缀物, 与功能分子发生 Cue-AAC 反应的单
取代叠氮或炔基底物的投料量需过量 20\%，产率 79\% $93 \%$.
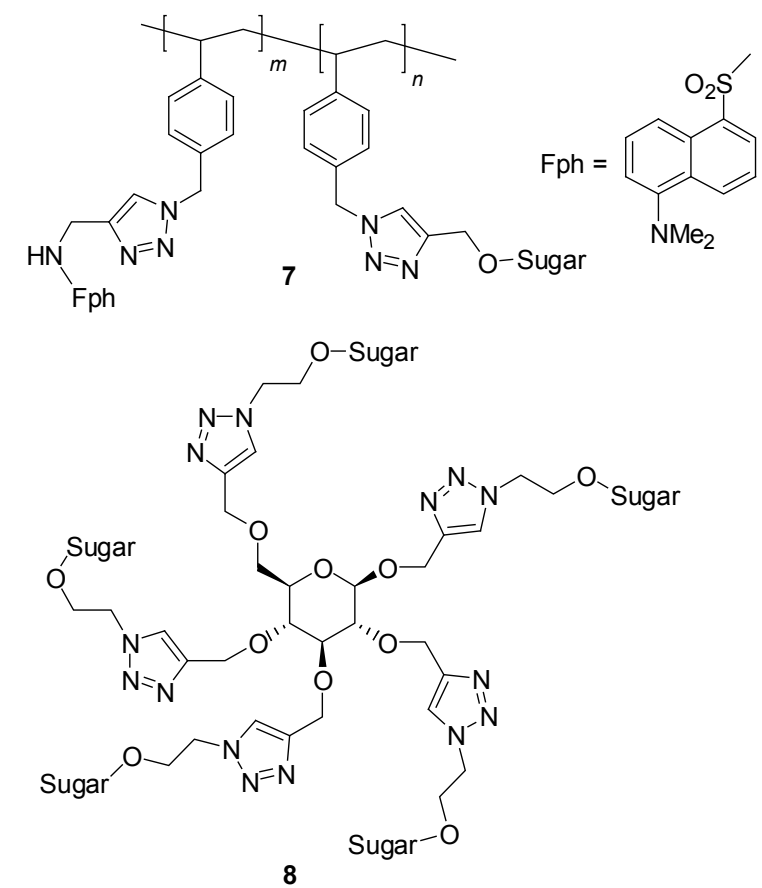

Scheme 6

Munteanu 等 ${ }^{883}$ 利用 1,7-辛二炔、单- $\mathrm{N}_{3}-\mathrm{CD}$ 和 1- $\mathrm{N}_{3}$ 金刚烷(Ad), 在微波辅助( $\left.130 \mathrm{~W}, 120{ }^{\circ} \mathrm{C}, 20 \sim 30 \mathrm{~min}\right)$ 的 条件下通过 Cue-AAC 反应合成了 CD-CD, CD-Ad, Ad-Ad (Scheme 7,9)等主体或客体分子. Cue-AAC 反应 的催化剂为 $\mathrm{CuSO}_{4} / \mathrm{NaAsc}, \mathrm{DMF}$ 作溶剂. 他们还通过动 态光散射实验 $(\mathrm{DLS})$ 考察了 $\mathrm{CD}-\mathrm{CD}$ 与 $\mathrm{CD}-\mathrm{Ad}, \mathrm{Ad}-\mathrm{Ad}$ 之 间的主-客体作用以及自组装能力.

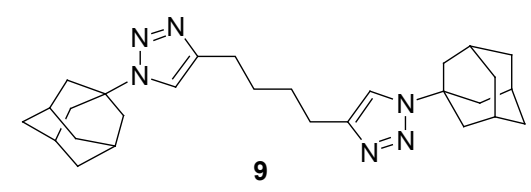

Scheme 7

同年, Munteanu 等 ${ }^{[84]}$ 以甲基丙烯酸炔丙酯、叠氮功 能化的 $\mathrm{CD}$ 为原料, 分别在常规条件 $\left(140{ }^{\circ} \mathrm{C}, 24 \mathrm{~h}\right)$ 以及 在微波辅助 $\left(100 \mathrm{~W}, 140{ }^{\circ} \mathrm{C}, 30 \mathrm{~min}\right)$ 的条件下通过 Cue-AAC 反应合成了 $\mathrm{CD}$ 功能化的甲基丙烯酸酯单体. 结果表明, 微波辅助可以明显提高点击反应的区域选择 性.

\subsection{6 卟啉衍生物}

点击化学已应用于卟啉衍生物的合成 ${ }^{[85,86]}$, 卟啉衍 生物中的糖-吓啉在药物化学及糖生物学领域具有广阔 的前景 ${ }^{[87 ~ 90]}$. 糖一卟啉缀合物形式的光敏剂糖基部分和 三唑环 ${ }^{[11]}$ 都具有很好的代谢稳定性. 糖类物质还能提高 
卟啉的水溶性，改善卟啉疗法的靶向功能 ${ }^{[92]}$.

Locos 等 ${ }^{[93]}$ 用传统和微波加热方式研究了叠氮一锌 卟啉与全乙酰化 $\beta$-炔丙基葡萄糖苷之间的点击反应，发 现微波加热能使反应时间由 $3 \mathrm{~d}$ 降到 $20 \mathrm{~min}$. 反应以甲 苯/水 $(V / V=4: 1)$ 为溶剂, 在 $\mathrm{CuCl}$ 催化, $140{ }^{\circ} \mathrm{C}$ 条件下 反应 $20 \mathrm{~min}$, 产率为 $93 \%$; 而以四氢呋喃/水 $(V: V=4$ : 1)为溶剂, 将反应温度降到 $80{ }^{\circ} \mathrm{C}$, 反应 $40 \mathrm{~min}$, 产率为 $81 \%$ (Eq. 13). 他们还合成了葡萄糖-甘露糖一锌卟啉以 及三、四糖基修饰的锌卟啉，并认为利用该方法能应用 于很成外围接有大量糖基的糖一卟啉树状分子.

类似地, Garcia 等 ${ }^{[94]}$ 最近分别用 $\mathrm{CuCl}$ 和 $\mathrm{CuSO}_{4} / \mathrm{NaAsc}$ 作催化剂以叠氮功能化和炔基功能化的 锌卟啉为核心, 与相应的糖配基在微波加热条件下进行 Cue-AAC 反应，反应时间 3 20 min，产率优良. 与上面 例子相比，间隔臂的长度以及三唑环的取向有所不同.

血管内皮生长子(VEGF)在肝癌中高表达, 对肝癌 新生血管形成及肿瘤生长和转移起重要作用. 以 VEGF 及其受体 VEGF-R 为靶点治疗癌症是药物研究的热点. Bakleh 等 ${ }^{[95]}$ 报道了卟啉分子通过微波辅助 Cue-AAC 反
应与四缩乙二醇柔性连接臂结合，连接臂末端的氨基再 与 VEGF 序列的环肽支架以酰胺键的形式结合，得到一 种光敏性的生物缀合物，可应用于针对 VEGF-R2 和肿 瘤新血管系统靶向的光动力疗法.

自 1994 年, Gust 等制备出第一个以共价键相连的卟 啉-富勒烯化合物以来，大量卟啉-富勒烯化合物被合成 与研究 ${ }^{[96,97]}$, 此类化合物主要被用于人工模拟生物体光 合作用、光电材料等.

Fazio 等 ${ }^{[98]}$ 通过 Cue-AAC 反应合成了三唑环连接的 卟啉-富勒烯化合物. 底物叠氮苯基卟啉是通过氨苯基卟 啉重氮转移反应制备, 炔基化的苯甲醛是通过商品三甲 基硅基保护的类似物脱保护而来. 两者在 $\mathrm{CuI} / \mathrm{NaAsc} /$ TBTA 催化体系作用下，以 $\mathrm{DMSO} / \mathrm{H}_{2} \mathrm{O}$ 为溶剂，微波(50 $\mathrm{W}, 80{ }^{\circ} \mathrm{C}$ )加热 $30 \mathrm{~min}$, 产率为 $84 \%$. 而以炔基功能化卟 啉与叠氮功能化苯甲醛为底物在相同的条件操作该反 应，产率仅为 $40 \%$. 最后，Cue-AAC 反应产物与肌氨酸 形成甲亚胺叶立德与富勒烯进行 Prato 1,3-偶极环加成 反应得到卟啉-富勒烯化合物(Scheme 8,10 和 11).

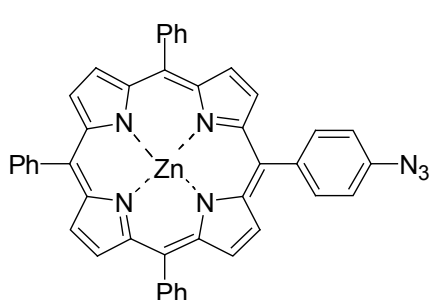

$\mathrm{Ph}$

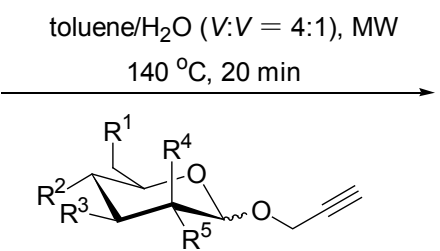

(1) $R^{1}=R^{2}=R^{3}=R^{5}=O A c, R^{4}=H$

(2) $R^{1}=R^{2}=R^{3}=R^{4}=O A c, R^{5}=H$

(3) $R^{1}=R^{2}=R^{3}=R^{4}=O H, R^{5}=O A C$

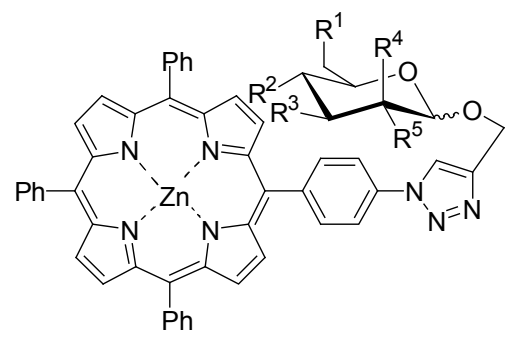

(1) $R^{1}=R^{2}=R^{3}=R^{5}=O A c, R^{4}=H$

(2) $R^{1}=R^{2}=R^{3}=R^{4}=O A c, R^{5}=H$

(3) $R^{1}=R^{2}=R^{3}=R^{4}=O H, R^{5}=O A C$

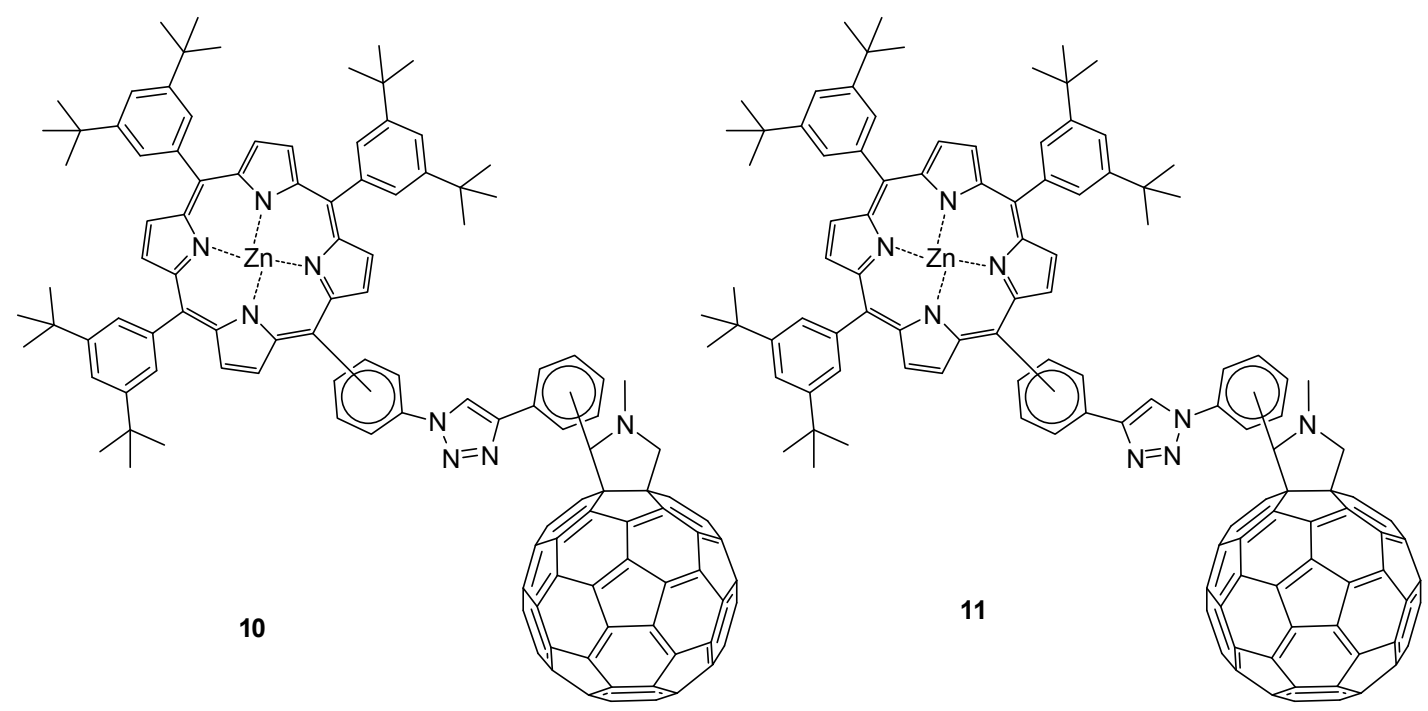

Scheme 8 


\subsection{7 其它}

Isobe 等 ${ }^{[99]}$ 合成了富勒烯-糖缀合物, 他们是用炔基 功能化的富勒烯 ${ }^{[100,101]}$ 与叠氮化的麦芽三糖作原料, $\mathrm{CuBr} / i$-DIPEA 为催化剂体系, 在 DMSO 中, $50{ }^{\circ} \mathrm{C}$ 微波 加热 $15 \mathrm{~min}$, 产率为 $93 \%$. 而同一个反应在普通加热 $(50$ ${ }^{\circ} \mathrm{C}$ )的条件下, 反应 $3 \mathrm{~d}$, 产率为 $91 \%$. 通过这种方法最 多可以在富勒烯分子上修饰 15 个糖基, 它们都具有纳 米尺寸的结构, 其半径各不相同.

Dondoni 等 ${ }^{[102]}$ 合成了通过三坐环连接的 $\alpha-D$-甘露 糖寡聚物(Scheme 9). 他们通过微波辅助 Cue-AAC 反应 将正交取代的乙炔基 $\alpha-C$-甘露糖和烷基 $6-\mathrm{N}_{3}-\alpha-C$-甘露 糖以三唑环连接起来, 其中乙炔基 $\alpha-C$-甘露糖上未保护 的羟基可以转化为叠氮基继续进行微波辅助 Cue-AAC 反应.
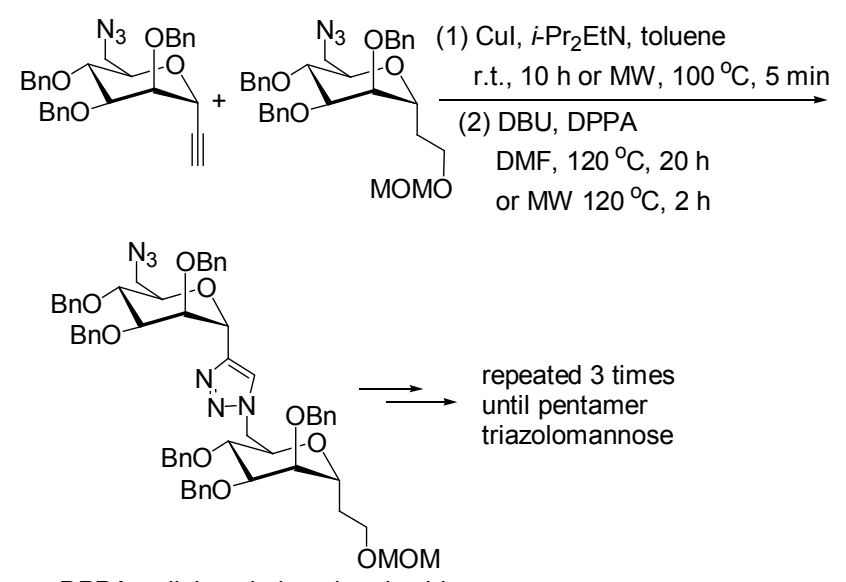

DPPA $=$ diphenyl phosphoryl azide

\section{Scheme 9}

\section{4 寡核苷酸及 DNA 类似物}

与合成肽类似物相似, 将磷酸链接基用三唑环代 替, 用点击聚合的方式可合成三唑环链接的寡核苷酸 ( ${ }^{\mathrm{TL}} \mathrm{DNA}$ ) (Scheme 10). 聚合反应在 THF 溶剂中进行, 15 $\mathrm{h}$ 后得到二聚体的产率为 $82 \%$. 由于二聚体在 THF 中溶 解度很小, 将溶剂改为 $\mathrm{THF} / t-\mathrm{BuOH} / \mathrm{H}_{2} \mathrm{O}$ 后得到三聚体 的产率为 $76 \%$. 研究表明, 以 THF 作溶剂时, 微波辐射 能大幅度加速反应进程.

若采用固相合成方法在 THF 溶剂中并用 $50{ }^{\circ} \mathrm{C}$ 微波 辐射, 则反应在 $90 \mathrm{~min}$ 内得到的三聚体产率为 $84 \%$. 经 过脱保护/链延长循环共 19 步反应后, 得到最终十聚体 产物的产率为 $0.61 \%{ }^{[103]}$. 研究表明, 固相合成与微波辐 射相相结合比在溶液中进行聚合反应要快得多.

相反, Morvan 等 ${ }^{[104]}$ 发现在合成单环、单环单枝、单 环双枝、双环等环形寡核苷酸时, 在溶剂 $[V(\mathrm{MeOH})$ : $\left.V\left(\mathrm{H}_{2} \mathrm{O}\right)=1: 1\right)$ 中聚合显然要比固相合成效率更高. 60
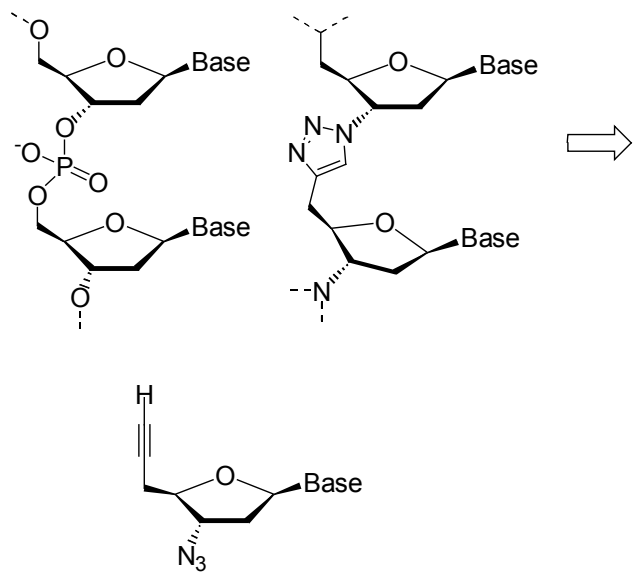

Scheme 10

${ }^{\circ} \mathrm{C}$ 微波辐射能提高反应速率, 减少副产物的生成. 反应 仅需 60 90 min 即可高产率获得目标物环形塞核苷酸. 该课题组还报道了采用胺化氧化和 Cue-AAC 反应对寡 核苷酸 $5^{\prime}$ 位进行功能化 ${ }^{[105]}$. 他们先后在 $5^{\prime}$ 位上进行炔功 能化和叠氮功能化, Cue-AAC 反应在微波加热下 $\left(60{ }^{\circ} \mathrm{C}\right)$ 进行, 溶剂为 $\left(\mathrm{MeOH} / \mathrm{H}_{2} \mathrm{O}=1 / 1, V / V\right)$, 在催化剂 $\mathrm{CuSO}_{4} / \mathrm{NaAsc}$ 存在条件下与相应的叠氮功能化的半乳 糖或炔功能化的甘露糖反应 $30 \mathrm{~min}$ (Scheme 11, 12). 所 有的步骤都可以在固载基上进行，这种合成策略也可应 用于在序列的不同位置(3'和 $\left.5^{\prime}\right)$ 上连有一个炔基和一个 $H$-磷酸双酯连接器的寡核苷酸.

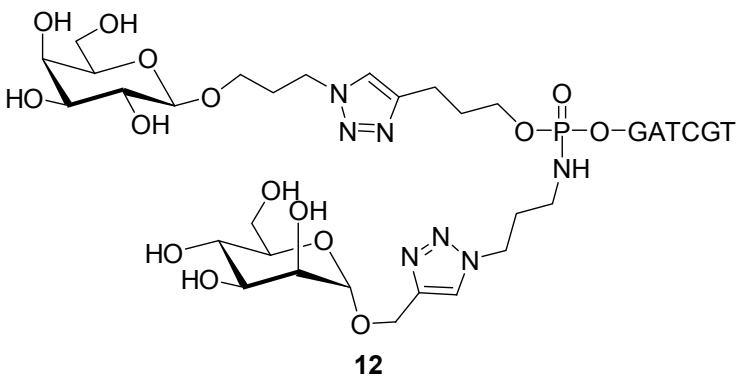

Scheme 11

将小分子化合物与寡核苷酸类药物结合，可增强细胞 对药物的摄取 ${ }^{[106,107]}$, 改善药物动力学及药效学性质 ${ }^{[108]}$. Yamada 等 ${ }^{[109]}$ 通过 Cue-AAC 反应在小分子干扰 RNA (siRNAs)中核糖基部分的 $2^{\prime}, 3^{\prime}$ 及 $5^{\prime}$ 位与小分子化合物键 合. 先将炔基功能化的寡核糖核苷酸片段固载在可控孔 度玻璃 $(\mathrm{CPG})$ 载体上, 再与叠氮化的长链脂肪烃、胆固醇 等进行 Cue-AAC 反应 (Eq. 14). 反应以 $\mathrm{CuSO}_{4} /$ $\mathrm{NaAsc} / \mathrm{TBTA}$ 为催化剂体系, 溶剂为 $\mathrm{H}_{2} \mathrm{O} / \mathrm{MeOH} / \mathrm{THF}$ $(V: V: V=2: 2: 1)$, 微波 $60{ }^{\circ} \mathrm{C}$ 加热 $45 \mathrm{~min}$, 产率最 高可达 99\%.

研究结果表明, 如果氨基糖苷类物质与寡核苷酸或 


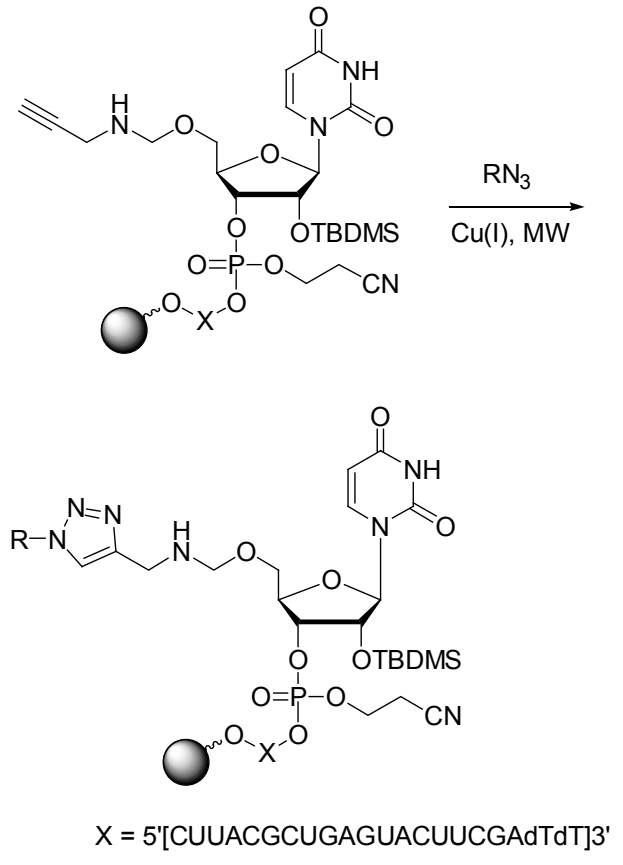

肽核酸(PNAs)结合, 产物可以表现为选择性人工核糖核 酸 ${ }^{[110,111]}$. Robles 等 ${ }^{[12]}$ 报道了氨基糖苷类抗生素新霉素 和巴龙霉素与二核苷酸和二肽核酸通过微波辅助的 Cue-AAC 反应键合起来(Eq. 15). 这些结合物包含不同 的氨基糖苷、碱基序列、寡核苷酸骨架等，用以研究其 与 RNA 次级结构之间特异的相互作用. 并且可以为设 计新型的 RNA 配体提供新的思路. 反应中以 $\mathrm{CuSO}_{4} / \mathrm{NaAsc}$ 为催化剂, 但 $\mathrm{Cu}(\mathrm{II})$ 与氨基糖苷结合会促 使后者降解 ${ }^{[13]}$, 故须先原位生成 $\mathrm{Cu}(\mathrm{I})$ 生成以后再加入 反应底物, 加入 TBTA 有助于 $\mathrm{Cu}(\mathrm{I})$ 的稳定. 值得指出的 是, 该反应是在水溶液中进行, 这也是点击反应发展的 一个趋势.

aminoglycoside $-\mathrm{N}=\mathrm{N}^{+}=\mathrm{N}^{-}+\equiv\left(\mathrm{H}_{2} \mathrm{C}\right)_{4} \mathrm{O}-\begin{gathered}\text { dinucleotide } \\ \text { or diPNA }\end{gathered}$

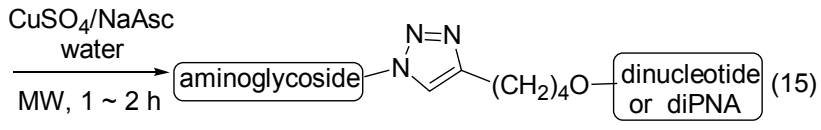

通过微波辅助点击反应的方法对核苷酸或核酸进 行修饰能获得三螺旋形成寡聚核苷酸(TFOs), 是一种非 常有前途的基因疗法以及作为生物纳米技术的在工 具 ${ }^{[14]}$. 在 DNA 序列中插入炔基官能团作为点击反应的 必备原料，与芳基或烷基叠氮化物一起在 $\mathrm{Cu}(\mathrm{I})$ 存在的 条件下, $70{ }^{\circ} \mathrm{C}$ 微波辐射 $2 \mathrm{~min}$, 产率 $45 \%$ (Eq. 16). 值得 一提的是, 由于 $\mathrm{Cu}^{2+}$ 在有 $\mathrm{O}_{2}$ 存在条件下会导致 DNA 裂 解, 故反应中采用 $\mathrm{Ar}$ 保护. 另外, 同样的反应用常规的 方法反应 $24 \mathrm{~h}$, 产率仅为 $30 \%{ }^{[115]}$.
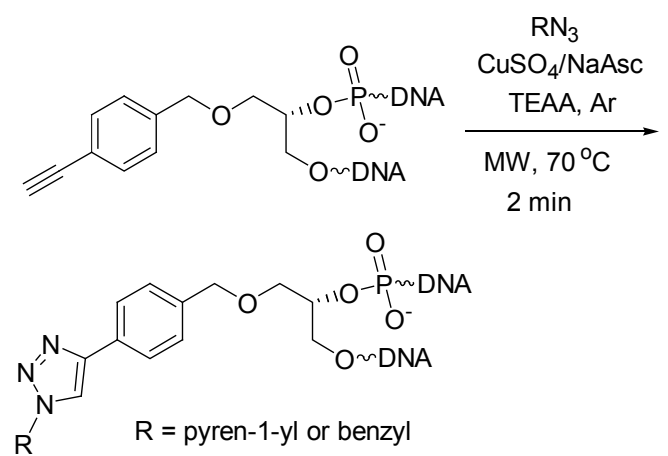

\section{2 小分子化合物}

\section{1 小分子核苷、核苷酸}

三唑杂环化合物被认为是一类强有效的抗菌、抗病 毒及抗增殖化合物，在制药领域具有相当重要的地位. Krim 等 ${ }^{[116]}$ 报道了通过 $N$-9-炔丙基嘌呤、 $N$-1-炔丙基嘧 啶、 $N-2$-炔丙基吲唑与假叠氮糖(或称叠氮糖前体化合 物)在微波辐射条件下的 Cue-AAC 反应合成了三唑环和 双三唑环连接的阿昔洛韦的非环核苷类似物 (Scheme 12,12 和 13). 反应以 $\mathrm{CuI}$ 为催化剂, 并有 $\mathrm{Et}_{3} \mathrm{~N}$ 存在于反 应体系中, $1 \mathrm{~min}$ 后，产率大于 $90 \%$. 而反应若在室温下 进行，则需 $3 \mathrm{~h}$, 产率 $80 \% \sim 90 \%$.

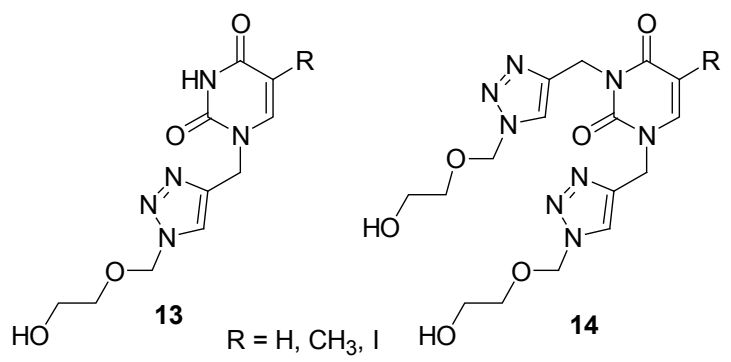

Scheme 12

点击反应也被用来对核苷进行修饰，Pradere 等 ${ }^{[117]}$ 通过不同的炔，在 $\mathrm{Cu}(\mathrm{I})$ 和 $\mathrm{Ru}(\mathrm{II}) \mathrm{Cp} * \mathrm{RuCl}\left(\mathrm{PPh}_{3}\right)_{2}$ 催化剂 作用下与 $1^{\prime}-\mathrm{N}_{3}-2^{\prime}, 3^{\prime}, 5^{\prime}$-三- $O$ - 茮基化核糖进行点击反应, 生成 1,4-和 1,5-二取代三唑环衍生物, 即利巴韦林类似 物 ${ }^{[18]}$. 前者只在普通加热方式下进行，而后者则分别 在普通和微波加热方式下进行(Eq. 17). 结果表明, 微波 辅助的 RuAAC 反应使反应时间由 $6 \mathrm{~h}$ 缩短到 $5 \mathrm{~min}$, 产 率高达 95\%以上.

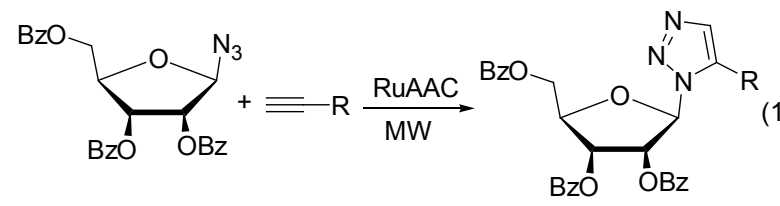

另外, Fokin 等 ${ }^{[119]}$ 也利用微波辅助的 RuAAC 反 应 $^{[120]}$ 合成了一系列以叠氮化芳基衍生物与炔基化合物 
为原料生成的 $1,5-$ 二取代三唑环衍生物. 反应在 DMF 中 进行, 微波加热温度为 $90 \sim 110{ }^{\circ} \mathrm{C}$, 反应 $20 \mathrm{~min}$, 产率 为 $43 \% \sim 92 \%$. 值得注意的是 $[\mathrm{Cp} * \mathrm{RuCl}]_{4}$ 在 $\mathrm{DMF}$ 中的效 果好于 $\mathrm{Cp} * \mathrm{RuCl}\left(\mathrm{PPh}_{3}\right)_{2}$.

Akri 等 ${ }^{[121]}$ 用 $1^{\prime}-\mathrm{N}_{3}-2^{\prime}, 3^{\prime}, 5^{\prime}$-三- $O$-苠基化核糖与端炔 在无溶剂条件下进行微波辅助 $\left(110{ }^{\circ} \mathrm{C}\right)$ 或在 $\mathrm{CH}_{2} \mathrm{Cl}_{2}$ 中且 有 $\mathrm{AcOH}$ 存在的情况下进行常规加热的 Cue-AAC 反应. 第一种途径将所有反应原料均分散在 $\mathrm{SiO}_{2}$ 上，反应 1 $\min$ 即定量得到立体与区位选择性专一的 $N$-核苷. 他们 通过对比实验发现在反应液中有 $\mathrm{SiO}_{2}$ 或 $\mathrm{AcOH}$ 等 Brønsted 酸存在的情况下, 反应产率相对较高. 相似地, 将 $\alpha$-或 $\beta$-叠氮-2-脱氧核糖与端炔在加热到 $110{ }^{\circ} \mathrm{C}$ 条件 下，以甲苯为溶剂, Cue-AAC 反应 $24 \mathrm{~h}$, 产率可达 $87 \%$. 若将所有反应原料均分散在 $\mathrm{SiO}_{2}$ 上, 并施以微波加热, 3 $\min$ 后产率即高达 $93 \%{ }^{[122]}$.

炔功能化的吡嗪与保护的叠氮功能化糖在 $\mathrm{Cu}(0) / \mathrm{Cu}(\mathrm{II})$ 作催化剂, $5 \mathrm{~mol} \%$ TBTA 作为 $\mathrm{Cu}(\mathrm{I})$ 配体, 在 $\mathrm{THF} / i-\mathrm{PrOH} / \mathrm{H}_{2} \mathrm{O}(V: V: V=3: 1: 1)$ 溶剂中, 微波加 热 $20 \mathrm{~min}\left(200 \mathrm{~W}, 90{ }^{\circ} \mathrm{C}\right)$, 得到一系列核苷类似物, 产 率 38\% 92\% (Eq. 18) ${ }^{[123]}$.

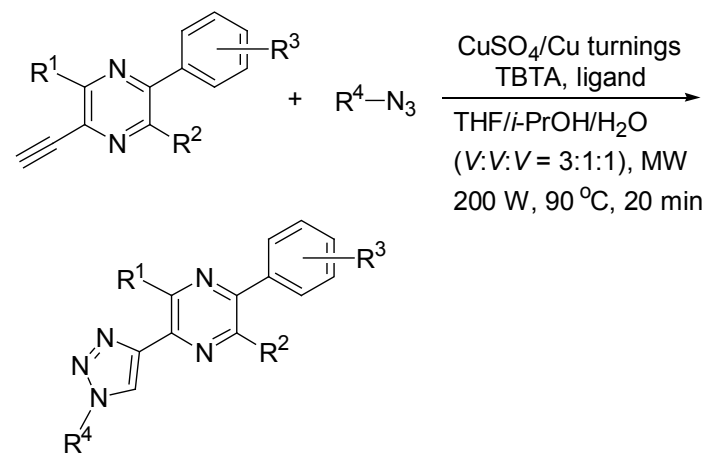

炔功能化的呋喃吡嗪与不同叠氮功能化的 $D$-核糖 和 2-D-脱氧核糖在 $\mathrm{Cu}(\mathrm{I})$ 催化剂作用下, 通过三唑环连 接生成了一系列核苷类似物. 反应以 $\mathrm{THF} / i-\mathrm{PrOH} / \mathrm{H}_{2} \mathrm{O}$ $(V: V: V=3: 1: 1)$ 作溶剂, $\mathrm{Cu}(\mathrm{I})$ 是由 $\mathrm{Cu}(0)$ 与 $\mathrm{CuSO}_{4}$ 溶液原位生成, TBTA 作为 $\mathrm{Cu}(\mathrm{I})$ 配体, $90{ }^{\circ} \mathrm{C}$ 微波加热 5 10 min, 产率最高可达 91\% (Eq. 19) ${ }^{[124]}$.

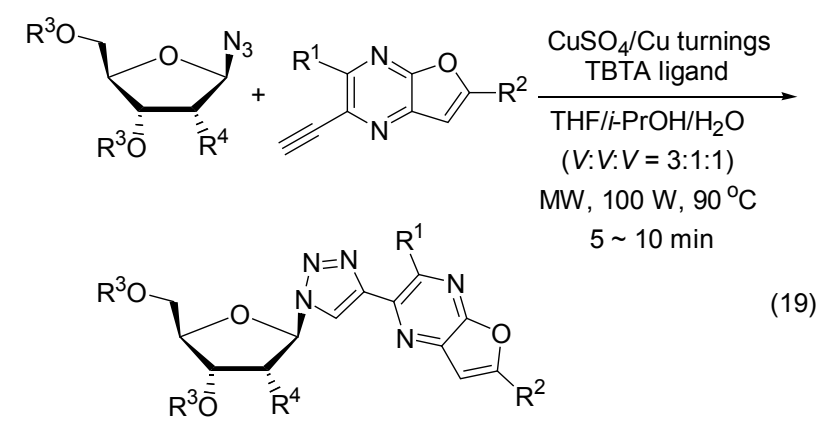

有趣的是，若此处的叠氮糖用 $2-\mathrm{N}_{3}-4,4$-二羟甲基环 戊醇代替, 作为 $\mathrm{N}_{3}$-源与炔衍生物进行微波辅助的 Cue-AAC 反应，产物可称作碳核苷(Eq. 20). 反应中，溶 剂为 $t-\mathrm{BuOH} / \mathrm{H}_{2} \mathrm{O}(V: V=1: 1), \mathrm{Cu}(0) / \mathrm{CuSO}_{4}$ 体系作为 催化剂体系, 反应时间由数分钟到 $1 \mathrm{~h}$, 产率都较高. 他 们还考察了 $\left(\left[\mathrm{Cu}\left(\mathrm{CH}_{3} \mathrm{CN}\right)_{4}\right] \mathrm{PF}_{6}\right)(\mathrm{Imes}) \mathrm{CuBr}$ 等其它催化 剂, 但效果都不如 $\mathrm{Cu}(0) / \mathrm{CuSO}_{4}$ 体系理想 ${ }^{[125,126]}$.

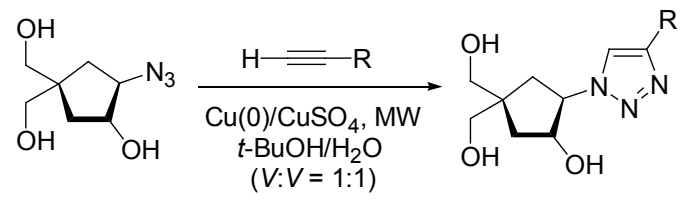

当 $\mathrm{N}_{3}$-源为 1- $\mathrm{N}_{3}-2,2$-二羟基-4-羊全甲基环戊醇时，其 它反应条件大概一致, $125{ }^{\circ} \mathrm{C}$ 温度下微波辐射 $1 \sim 15$ $\min$ 得到 1,4-二取代 $D$ - $(-)-1,2,3$-三唑-碳核苷, 产率最 高达 $98 \%{ }^{[127]}$. 这些产物虽然含有三唑环结构, 但是没有 细胞毒性. 研究还表明三唑环并不是抑制天花的主要原 因，这就说明此处的叠氮化物不单局限于形成三唑环的 前体，也能与其它非炔衍生物的分子反应，丰富碳核苷 的种类及应用范围.

Lucas 等 ${ }^{[128]}$ 研究了以 $5-\mathrm{N}_{3}$-胸腺嘧啶脱氧核苷与 3炔丙氧基胸腺嘧啶脱氧核苷为前体, 利用微波辅助的 Cue-AAC 反应合成了以三唑环连接的胸腺嘧啶脱氧核 苷二聚体(Eq. 21). 他们分别使用了 CuI/DIPEA 与 $\mathrm{CuSO}_{4} / \mathrm{NaAsc}$ 为催化体系. 微波辐射使时间由 $5 \mathrm{~h}$ 缩短 为 $3 \mathrm{~min}$, 产率优良 $(61 \% \sim 81 \%)$.

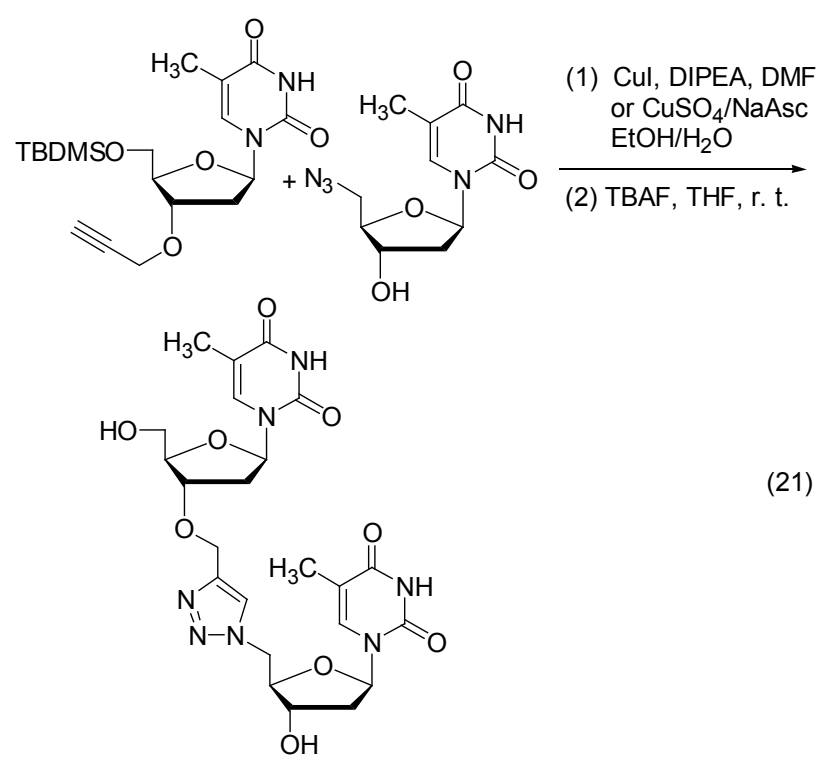

若 3-炔丙氧基胸腺嘧啶脱氧核苷结构中核糖 5 号位 接有一个 $\mathrm{Ts}$ 基团，则其根据上述合成方法获得二聚体 后, 可将 $\mathrm{Ts}$ 基团转化为叠氮基团, 再重复进行微波辅助 的 Cue-AAC 反应，可获得寡聚胸腺嘧啶脱氧核苷 ${ }^{[129]}$. 
Lin 等 ${ }^{[130]}$ 利用微波辅助 Cue-AAC 反应合成了一系 列抑制人类细胞质胸苷激酶(hTK1)和溶艮艮孢子虫胸 苷激酶(UpTK)的胸苷类化合物, 它们的前体化合物都 为 $3^{\prime}-\mathrm{N}_{3}-3^{\prime}$-脱氧胸苷 (AZT). 由于两种酶的活性位点中 的核苷的结合模式不同，使得上述两种胸苷类化合物的 酶抑制活性有所差异(Eq. 22).

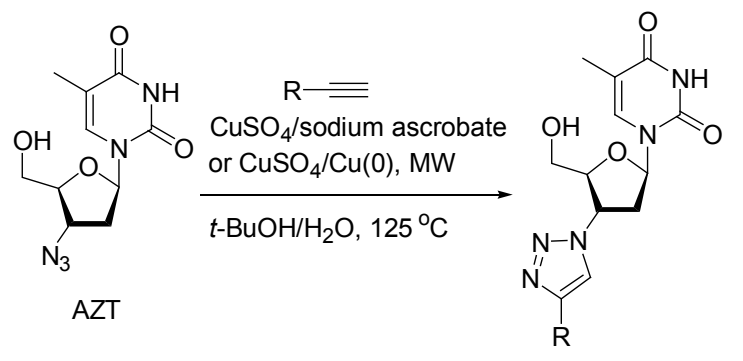

最近, 该课题组 ${ }^{[131]}$ 又利用微波辅助 Cue-AAC 和 RuAAC 反应合成了一系列碱基 C-5 位上 1,4-和 1,5-二取 代的三唑环 $2^{\prime}$-脱氧尿苷衍生物. 这些衍生物大都具有 针对单纯疮疹病毒、水痘带状疮疹病毒和牛痘病毒等的 抗病毒活性.

\section{2 一锅法合成小分子}

早在 2003 年, Savin 等 ${ }^{[132]}$ 就通过一系列的小分子模 型反应考察了温度、浓度、时间、溶剂等因素对微波辅 助 Cue-AAC 反应产率的影响. 发现升高温度和浓度可 以缩短反应时间.

2004 年, Appukkuttan 等 ${ }^{[133]}$ 报道了以卤代物、叠氮化 钠、炔衍生物为原料, 一锅法合成了一系列 1,4-二取代1,2,3-三唑化合物. 他们先将三种原料分散在叔丁醇/水 $(V / V=1 / 1)$ 的混合溶剂中, 加入 $\mathrm{Cu}(0)$ 与 $\mathrm{Cu}(\mathrm{II})$ 组分, 利用 它们之间的反歧化反应得到 $\mathrm{Cu}$ (I) 催化剂. 在微波功率 100 $\mathrm{W}$, 温度 $125{ }^{\circ} \mathrm{C}$ 的条件下反应 $10 \mathrm{~min}$, 冷却至室温, 产物 直接在反应液中重结晶, 过滤得到纯净产品, 产率 $>90 \%$.

这种合成方法省去了单独合成有机叠氮化物的分 离、提纯步骤，也减少了某些小分子叠氮化物不稳定给 后续反应带来不利影响的可能性. 简单分离后高产率得 到了区位选择性为 $100 \%$ 的 1,4-二取代产物. 使得其成 为一种理想的多组分点击反应.
Johansson 等 ${ }^{[134]}$ 则以 $\left[\mathrm{RuClCp} *\left(\mathrm{PPh}_{3}\right)_{2}\right]$ 作催化剂, 二 甲胺作溶剂, 利用微波辅助一锅法合成了区位选择性为 1,5-二取代的三唑环衍生物，产率 18\% 97\% (Eq. 23).

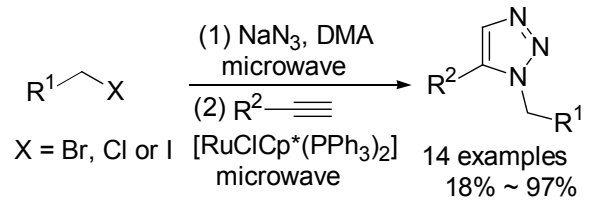

2008 年, Moses 等 ${ }^{[135]}$ 将苯胺衍生物与 $t$-BuONO 与 $\mathrm{TMSN}_{3}$ 混合，一锅法合成了叠氮化物，作为点击反应的 前体. 接着, 加入 $\mathrm{CuSO}_{4} \cdot 5 \mathrm{H}_{2} \mathrm{O}$ 和 $\mathrm{NaAsc}$ 水溶液原位生 成 $\mathrm{Cu}(\mathrm{I})$ 催化剂, 最后加入含有端炔基的化合物使其在 催化剂作用下与之前生成的叠氮化物发生点击反应 (Scheme 13). 对于此条合成路线, 该课题组分别在室温 及微波加热的条件下对反应进行了考察，发现后者能大 大缩短反应时间，提高产率. 他们选用的微波最大功率 为 $125 \mathrm{~W}$, 温度为 $80{ }^{\circ} \mathrm{C}$.

上述合成方法相比传统方法具有安全、纯化步骤 少、易于操作、高效等特点. 特别是在用到不稳定的小 分子叠氮化物和多元叠氮芳基化物时，其优势更为明 显.

而 Wittmann 等 ${ }^{[136]}$ 则是通过 $\mathrm{Cu}(\mathrm{II})$ 催化的重氮转移 反应与微波辅助 Cue-AAC 反应相结合实现一锅法合成 的. 只需在第一步反应完全后, 在反应器中投入 $\mathrm{NaAsc}$, TBTA 及炔衍生物, 并令反应体系处于微波加热 $\left(80{ }^{\circ} \mathrm{C}\right)$ 的条件下反应 $30 \mathrm{~min}$ ，产率 78\% 99\%。

另外, Biehl 等 ${ }^{[137]}$ 于 2009 年首次报道了苯炔、3-甲 氧基苯炔、4,5-二氟苯炔与叠氮衍生物经二组分和三组 分的方法在微波辅助下合成了苯并三唑衍生物(Eq. 24).

三组分反应中的叠氮衍生物是卤代烷与 $\mathrm{NaN}_{3}$ 原位生 成，而两种方法中的苯炔都是由 $o$-(三甲硅基芳基)三氟甲 基磺酸在 $\mathrm{CsF}$ 或 $\mathrm{KF} / 18$-冠-6 存在条件下生成的. $125{ }^{\circ} \mathrm{C}$ 微 波加热 15 20 min，得到产率优良的苯并三坐衍生物. 反 应时间比在室温下 $(18 \sim 24 \mathrm{~h})^{[138]}$ 大大缩短. 对比实验结果 发现 $\mathrm{KF} / 18$-冠-6 存在时, 产率高于 $\mathrm{CsF}$ 存在时的产率.

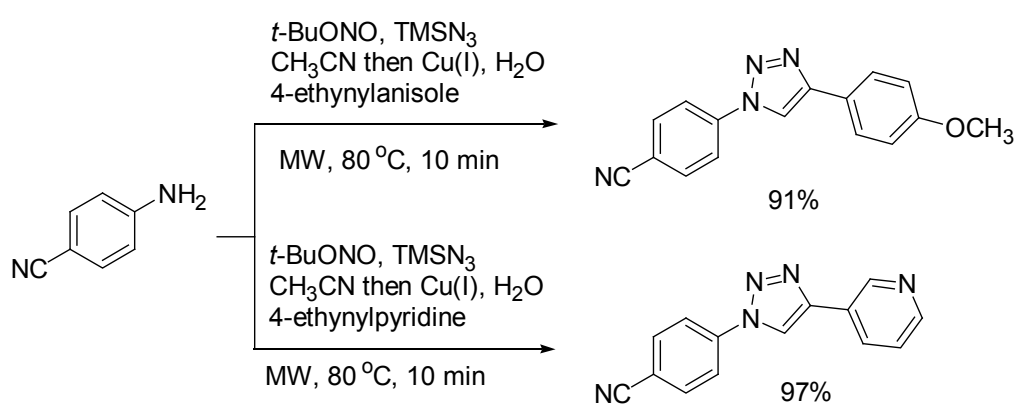

Scheme 13 


$$
\text { R-X+NaN3+ }
$$

Yang 等 ${ }^{[139]}$ 通过一锅连续加入烷基溴、 $\mathrm{NaN}_{3}$ 、丙炔 酸甲酯、胺类及 $\mathrm{Zr}(\mathrm{O} t-\mathrm{Bu})_{4}$ 合成了 $C$-氨基甲酰-1,2,3-三 唑衍生物, 产率最高可达 93\% (Scheme 14), 而将所有原 料一锅直接投入则总体产率只有 $25 \%$. 以上两条线路的 每个步骤均在微波下进行, 其中 Cue-AAC 反应是以 $\mathrm{CuI} / \mathrm{DIPEA}$ 作催化剂, $90{ }^{\circ} \mathrm{C}$ 微波加热 $30 \mathrm{~min}$, 功率为 $100 \mathrm{~W}$.

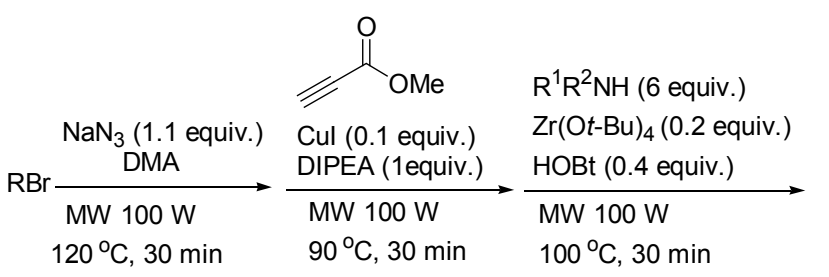

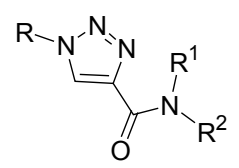

\section{Scheme 14}

\subsection{C-氨基甲酰-1,2,3-三唑衍生物}

酰胺键与三唑环相连的 $C$-氨基甲酰-1,2,3-三唑衍生 物具有很高的生物活性. 然而, 由于炔酰胺的 Cue-AAC 反应活性不高, 致使通过其合成上述一类物质成为一大 难题. 但当在无溶剂条件下对反应施以微波辐射(120 $170 \mathrm{~W}, 55 \sim 85{ }^{\circ} \mathrm{C}$ ), 时间仅为 $30 \mathrm{~min}$, 产率为 $62 \%$ $84 \%{ }^{[140]}$.

随后, 该课题组还用同样的方法合成了一系列含有 两个三唑环的 C-氨基甲酰-1,2,3-三唑衍生物. 以单叠氮 与双炔酰胺衍生物为原料，在无溶剂条件下，微波(100 $\left.\mathrm{W}, 55{ }^{\circ} \mathrm{C}\right)$ 加热 $30 \mathrm{~min}$, 得到目标产物的产率最高可达 $84 \%$. 然而, 这个条件并不适用于双叠氮与单炔酰胺衍 生物之间的反应, 操作下来只会生成单三唑环的衍生 物. 若将反应条件调整为: 甲苯作溶剂, 微波 $(100 \mathrm{~W}, 75$ ${ }^{\circ} \mathrm{C}$ ), 外部冷却 $1 \mathrm{~h}$, 产率最高可达 $65 \%{ }^{[141]}$.

若在无溶剂条件下有 $\mathrm{LiClO}_{4}$ 存在, 再对反应物进行 微波加热, 能使活性不高的炔发生 Cue-AAC 反应. 说明 $\mathrm{LiClO}_{4}$ 在反应中起着至关重要的作用 ${ }^{[142]}$.

\section{4 蛋白酪氨酸磷酸酶(PTP)抑制剂}

蛋白酪氨酸磷酸酶是与人类疾病密切相关的一类 蛋白质，包括自身免疫紊乱、糖尿病和癌症. 最近，陈国 荣等 ${ }^{[143]}$ 利用微波辅助 Cue-AAC 反应合成了三唑环连接 的苯丙氨酸和酪氨酸-芳基 $C$-糖苷化合物. 事实上, $C$-糖 苷键比 $O$-糖苷键具有更强的酸与酶耐受性, 并具有较 高的 PTP1B 抑制活性 ${ }^{[143]}$. 他们是通过炔基功能化的芳 基 $C$-糖苷与叠氮化的氨基酸衍生物在 $\mathrm{CH}_{2} \mathrm{Cl}_{2} / \mathrm{H}_{2} \mathrm{O}$ 混合 溶剂中, 以 $\mathrm{CuSO}_{4} / \mathrm{NaAsc}$ 为催化剂, 施以微波辐射(55 ${ }^{\circ} \mathrm{C}, 20 \mathrm{~min}$ ), 产率 $92 \%$ (Eq. 25), 产物脱苠基后的的产率 为 $44 \%$. 他们对这两种氨基酸-芳基 $C$-糖苷化合物的 PTP1B 抑制活性研究表明前者活性更高，可能是由于苠 基的存在能与外围酶的表面产生额外的非极性相互作 用, 增强了 PTP1B 亲和力 ${ }^{[144]}$.

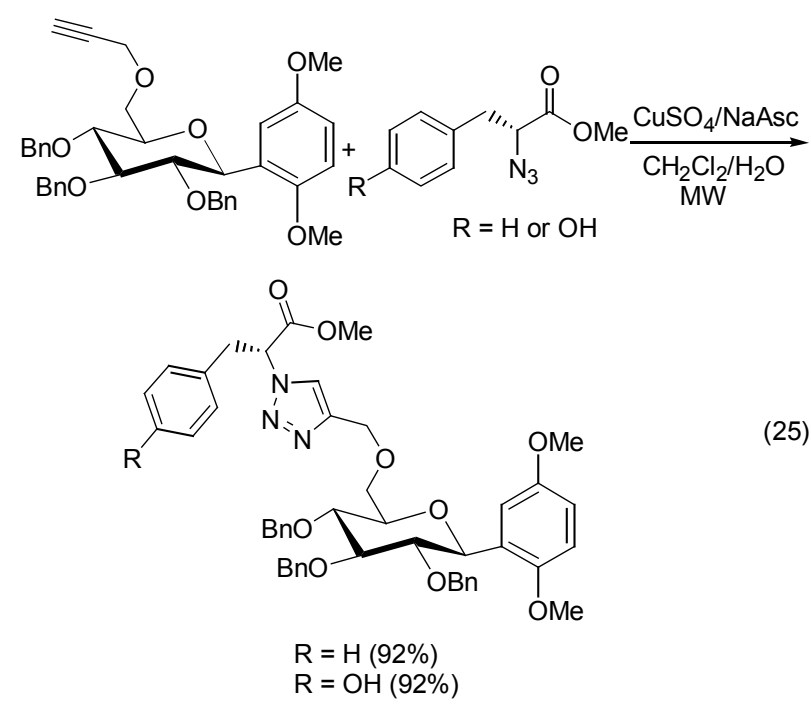

另外, 该课题组还通过微波辅助合成了三唑环连接 的葡萄糖基或半乳糖基丝氨酸、苏氨酸、苯丙氨酸、酪 氨酸衍生物, 作为新型的 PTP 和 CDC25B 抑制, 其效果 是其它同源 PTPs 的数倍 ${ }^{[145]}$. 双功能化的糖基-三唑环 氨基酸衍生物 ${ }^{[146]}$ 以及糖基-三唑环水杨酸衍生物 ${ }^{[147]}$ 也 同样被合成出来. 他们同样具有 PTP 抑制活性.

\section{5 香豆素荧光点击化学}

2011 年, 陈国荣等 ${ }^{[148]}$ 还报道了以 3 位 $\mathrm{N}_{3}$ 基取代的 香豆素与 3,4 位炔基取代的全保护的葡萄糖和半乳糖为 原料, $V(\mathrm{DMF}) / V\left(\mathrm{H}_{2} \mathrm{O}\right)=3 / 1$ 为溶剂, 在 $\mathrm{CuSO}_{4} / \mathrm{NaAsc}_{\text {催 }}$ 化作用下, $60{ }^{\circ} \mathrm{C}$ 微波加热 $30 \mathrm{~min}$, 产率分别为 $58 \%$ 和 $43 \%$ (Eq. 26). 产物的苂光性质由于富电子的 $\mathrm{N}_{3}$ 基的消 失得以再生, 糖基脱保护后, 该香豆素一糖化合物水溶 性大大提高, 光化学实验发现水溶液中的 $\mathrm{Ag}^{+}$可以使其 荧光淬灭, 故可以作为一种有效的化学传感器检测水溶 液或人体体液中的 $\mathrm{Ag}^{+}$浓度. 


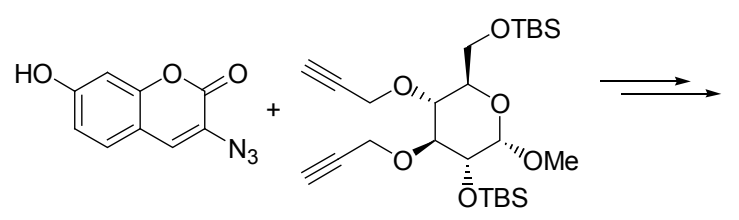<smiles>CO[C@H]1O[C@H](CO)[C@@H](O)[C@H](CO)[C@@H]1c1cn(-c2cc3ccc(O)cc3oc2=O)nn1</smiles>

结构与香豆素类似的物质也可应用于激光染料、苂 光标记、OLEDs、光学光亮剂 ${ }^{[149]}$. 在此结构上引入三唑 环能增强其苂光性质, 可实现特定生物分子及细胞表面 的可视化. 基于此, Kappe 等 ${ }^{[150]}$ 在 2007 年报道了合成了 一系列 3-和 4-三唑-2(1H)-喹啉酮化合物.

\section{6 其它}

Mayot 等 ${ }^{[151]}$ 用 2-全氟烷基乙基叠氮与炔酯或炔酸 用常规加热和微波加热两种方式来操作 Cue-AAC 反应 (Eq. 27). 结果表明, 在无溶剂条件下, $90{ }^{\circ} \mathrm{C}$ 加热 $6 \mathrm{~h}$, 而微波加热只需 $10 \mathrm{~min}$ 即可定量得到产物. 产物是一种 潜在的两亲性的分子，可用作表面活性剂.

$$
\begin{aligned}
& \mathrm{F}\left(\mathrm{CF}_{2}\right)_{n} \mathrm{CH}_{2} \mathrm{CH}_{2} \mathrm{~N}_{3} \stackrel{\mathrm{H}_{3} \mathrm{COOC}-\mathrm{COOCH}_{3}}{\mathrm{MW}} \\
& \mathrm{F}\left(\mathrm{CF}_{2}\right)_{n} \mathrm{CH}_{2} \mathrm{CH}_{2}-\mathrm{N}
\end{aligned}
$$

2010 年, 陈国荣等 ${ }^{[152]}$ 以异头碳叠氮化的葡萄糖以及 炔基功能化的烷基长链为构建板块, 利用微波辅助 Cue-AAC 反应合成了三唑环连接的糖脂衍生物, 并对其 肿瘤细胞毒性及金电极表面的吸附活进行了研究. 研究 表明, 疏水尾链的长短与奇偶效应对其性能均有影响.

唑是一类常见的抗真菌、抗过敏药物, 主要包括咪康 唑及其衍生物、咪唑类、三唑类等. 2007 年, Botta 等 ${ }^{[153]}$ 利用 Cue-AAC 反应能生成三唑环的特点、设计并合成 了一系列光学纯的 $\alpha$-[4-(1-取代)-1,2,3-三唑-4-芐基]乙酰 胺类化合物. 该反应使用微波加热 $\left(120{ }^{\circ} \mathrm{C}, t-\mathrm{BuOH} /\right.$ $\left.\mathrm{H}_{2} \mathrm{O}, \mathrm{CuSO}_{4} / \mathrm{NaAsc}\right) 10 \mathrm{~min}$ 后完全转化, 产率为 $75 \%$ $90 \%$.

联苯环辛二烯类木脂素(如五加前胡素)及其氮杂类 似物具有抗白血病的功能, 其合成方法一直备受科研工 作者的关注. Van der Eycken 小组 ${ }^{[154]}$ 报道了利用微波辅 助的 Suzuki 反应与 Cue-AAC 反应合成了这类物质(Eq. $28)$, 后者反应条件为邻二氯苯作溶剂, 微波(300 W, 120 $\left.{ }^{\circ} \mathrm{C}\right)$ 加热 $15 \mathrm{~min}$ 或 $\mathrm{DMF}$ 作溶剂, 微波 $\left(150 \mathrm{~W}, 80{ }^{\circ} \mathrm{C}\right)$ 加 热 $20 \mathrm{~min}$, 产率分别为 $43 \%$ 和 $76 \%$. 随后，他们还报道 了与此类似的相关工作 ${ }^{[155,156]}$.

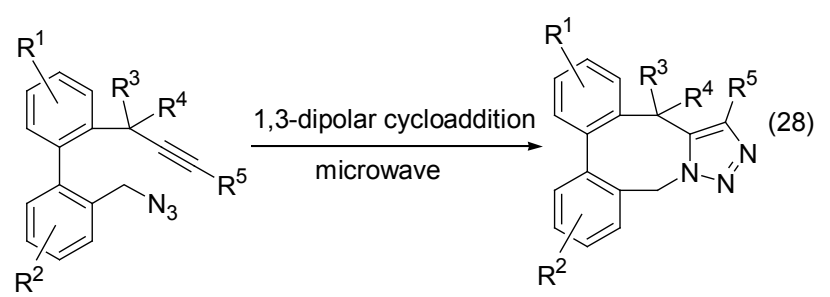

Kappe 等 ${ }^{[24]}$ 于 2004 年报道用微波辅助 Cue-AAC 反 应合成了 6-(1,2,3-三唑环)-1-嘧啶酩, Cue-AAC 反应前体 6- $\mathrm{N}_{3}$ 嘧啶酤是通过 $60{ }^{\circ} \mathrm{C}$ 微波加热 $20 \mathrm{~min}$ 制备出来的. 后续的环加成反应以 $\mathrm{DMF}$ 为溶剂, $\mathrm{CuSO}_{4} / \mathrm{NaAsc}$ 体系原 位生成 $\mathrm{Cu}(\mathrm{I})$ 催化剂, 微波加热 $1 \mathrm{~min}$ 得到环加成产物, 产率 $73 \%$ ，若反应在常温下进行则需要 $1 \mathrm{~h}$.

2005 年, Van der Eycken 等 ${ }^{[157]}$ 报道了利用微波辅助 的 Cue-AAC 反应对 2(1H)-吡嗪酮支架进行修饰(Scheme 15). 该反应在室温下进行需要 $36 \mathrm{~h}$, 在 $\mathrm{CuSO}_{4} / \mathrm{Cu}(0)$ 催 化剂体系存在下施以微波辐射, 可使反应缩短为 15 min, 加入 TBTA 配体则仅需 5 min.

Dedola 等 ${ }^{[158]}$ 运用微波辅助 Cue-AAC 反应的方法快 速合成了一个与三唑环相连的 $\alpha$-或 $\beta-N$-糖苷化合物库. 它们具有潜在的生物医用价值，譬如用作糖苷酶的抑制 剂. Kuang 等 ${ }^{[159]}$ 则利用微波辅助 Cue-AAC 反应合成了 一系列三唑环取代的苯乙炔衍生物. 他们的工作使微波 辅助 Cue-AAC 反应的应用范围朝着更深入、更普适的 方向发展.

\section{3 新型催化剂用于微波辅助 Cue-AAC 反应}

Cravotto 等 ${ }^{[160]}$ 用超声的办法制备了活性炭固载 $\mathrm{Cu}(\mathrm{I})$ 作为非均相催化剂, 在微波辅助下进行的一系列 Cue- AAC 反应. 若使用特殊的装置，使微波和超声辐 射能够同时作用于 Cue-AAC 反应体系，可得到更为理 想的结果 ${ }^{[161]}$.

Lipshutz 等 ${ }^{[162]}$ 也采用 $\mathrm{Cu}(\mathrm{I}) / \mathrm{C}$ 催化剂在微波辅助 $\left(120 \sim 150{ }^{\circ} \mathrm{C}\right.$, 二氧六环, 3 $10 \mathrm{~min}$ )催化 Cue-AAC 反 应合成了一系列小分子化合物, 并考察了碱 $\left(\mathrm{Et}_{3} \mathrm{~N}\right)$ 对 Cue-AAC 反应的影响, 发现碱的存在有利于阴离子的 形成和 $\mathrm{Cu}(\mathrm{I})$ 的稳定，因此可以提高反应速率.

Park 等 ${ }^{[163]}$ 也对点击反应催化剂作了创新，他们是 采用附着 $\mathrm{CuO}$ 空心纳米球的乙炔黑 $(\mathrm{CuO} / \mathrm{AB})$ 在微波作 用下合成了一系列小分子化合物，验证了其对催化点击 反应的高活性，反应在无溶剂条件下进行仅需 $1 \mathrm{~min}$ 即 可转化完全. 


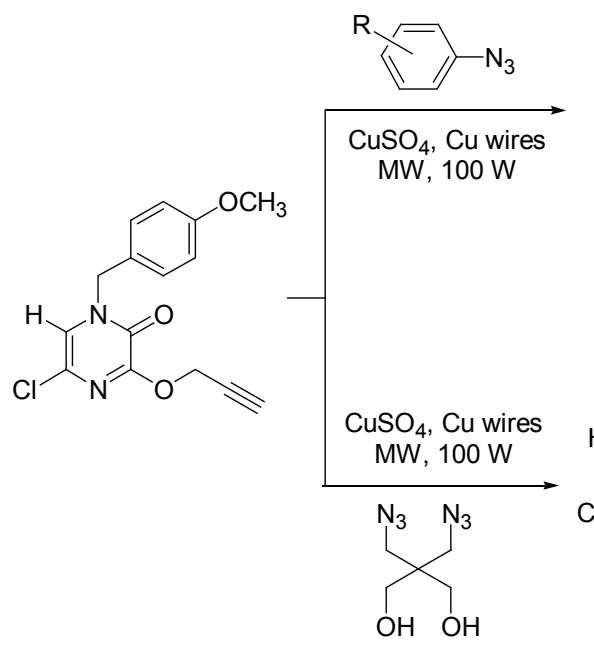

$\mathrm{CuSO}_{4}, \mathrm{Cu}$ wires

$\mathrm{OH} \mathrm{OH}$<smiles></smiles>

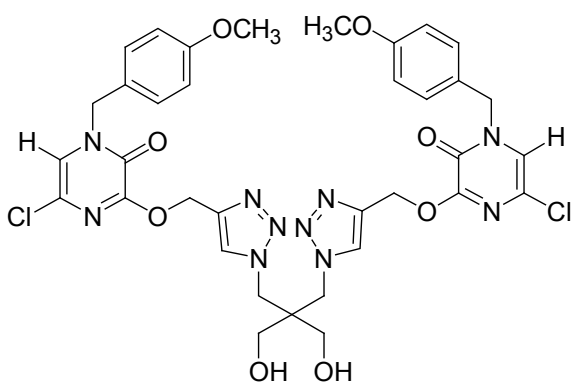

Scheme 15

最近, Alonso 等 ${ }^{[164]}$ 则利用 $\mathrm{Cu}$ 纳米粒子作为催化剂, 有 $\mathrm{Et}_{3} \mathrm{~N}$ 存在条件下, 在 THF 中进行微波辅助的点击反 应，合成了一系列小分子化合物，反应时间仅需 10 $120 \mathrm{~min}$. 他们还通过活性研究以及気实验论证了反应 机理中乙炔铜(I)是活性中间体.

\section{4 结束语}

自点击化学的概念提出十年以来, 由于其具有简 单、高效、通用等特点，已被广泛应用于生物大分子、 有机小分子、拓扑结构分子、大分子聚合物、纳米材料 的合成以及表面改性、苂光探针、药物靶向等诸多领域, 无论在研究热度还是广度、深度上都已然呈全盛之势. 微波辅助作为一项绿色合成技术在缩短反应时间、减少 副产物等方面优化了点击化学的进程, 为其发展注入新 的活力. 然而, 微波辅助点击化学就倡导绿色化学理念 方面而言尚存缺陷, 至今鲜有在纯水相中进行反应的报 道, 这将是人们下阶段研究的重要方向之一. 将绿色化 学的理念贯穿于点击化学之中将能持续推动点击化学 在更多领域中更广泛的应用. 另外, 在反应中引入其它 特殊反应条件, 如超声, 离子液体等, 有望能够使更多 的有机反应适用点击化学的概念.

\section{References}

[1] Kolb, H. C.; Finn, M. G.; Sharpless, B. K. Angew. Chem., Int. Ed. 2001, 40, 2004.

[2] John, E. M.; Adam, D. M. Chem. Soc. Rev. 2007, 36, 1249.

[3] Tornøe, C. W.; Christensen, C.; Meldal, M. J. Org. Chem. 2002, 67, 3057.

[4] Rostovtsev, V. V.; Green, L. G.; Fokin, V. V.; Sharpless, K. B. Angew. Chem., Int. Ed. 2002, 41, 2596.
[5] Morten, M.; Christian, W. T. Chem. Rev. 2008, 108, 2952.

[6] Wang, Q. Hawker, C. Chem. Asian J. 2011, 6, 2568.

[7] Liu, L. W.; Guo, W. B.; Li, X. C.; Qu, G. R.; Zhao, B. T. Chin. J. Org. Chem. 2010, 30, 1960 (in Chinese).

(刘连委, 郭文博, 李晓川, 渠桂荣, 赵邦屯, 有机化学, 2010, 30, 1960.)

[8] An, W.; Zhang, H. C.; Sun, T.; Li, X. J.; Hao, A. Y. Chin. J. Org. Chem. 2011, 31, 275 (in Chinese).

(安伟, 张华承, 孙涛, 李祥军, 郝爱友, 有机化学, 2011, 31, 275.)

[9] Giguere, R. J.; Bray, T. L.; Duncan, S. M.; Majetich, G. Tetrahedron Lett. 1986, 27, 4945.

[10] Barge, A.; Tagliapietra, S.; Binello, A.; Cravotto, G. Curr. Org. Chem. 2011, 15, 189.

[11] Kappe, C. O.; Dallinger, D. Mol. Diversity 2009, 13, 71.

[12] Appukkuttan, P.; Mehta, V. P.; Van der Eycken, E. V. Chem. Soc. Rev. 2010, 39, 1467.

[13] Cravotto, G.; Cintas, P. Chem. Eur. J. 2007, 13, 1902.

[14] Zhou, Z. Z.; He, Y. Z.; Cao, M.; Yang, G. F. Chin. J. Org. Chem. 2006, 26, 1500 (in Chinese).

(周中振, 何彦祯, 曹敏, 杨光富, 有机化学, 2006, 26, 1500.)

[15] Kappe, C. O. Chem. Soc. Rev. 2008, 37, 1127.

[16] Cruz, P.; Diez-Barra, E.; Loupy, A.; Longa, F. Tetrahedron Lett. 1996, 37, 1113.

[17] Moghaddam, F. M.; Dakamin, M. G. Tetrahedron Lett. 2000, 41, 3479.

[18] Lidstrom, P.; Tierney, J.; Wathey, B.; Westman, J. Tetrahedron 2001, 57, 9225.

[19] Perreux, L.; Loupy, A. Tetrahedron 2001, 57, 9199.

[20] Martellia, G.; Spuntaa, G.; Panunziob, M. Tetrahedron Lett. 1998, $39,6257$.

[21] Dawooda, K. M.; Kirschninga, A. Tetrahedron 2005, 61, 12121.

[22] Pedotti, S.; Patti, A. Organomet. Chem. 2008, 693, 1375.

[23] Hakkou, H.; Eynde, J. J. V.; Hamelin, J.; Bazureau, J. P. Tetrahedron 2004, 60, 3745.

[24] Khanetskyy, B.; Dallinger, D.; Kappe, O. J. Comb. Chem. 2004, 6, 884.

[25] Hill, D. J.; Mio, M. J.; Prince, R. B.; Hughes, T. S.; Moore, J. S. Chem. Rev. 2001, 101, 3893. 
[26] Gellman, S. H. Acc. Chem. Res. 1998, 31, 173.

[27] Smith, A. B.; Keenan, T. P.; Holcomb, R. C.; Sprengeler, P. A.; Guzman, M. C.; Wood, J. L.; Carroll, P. J.; Hirschmann, R. J. Am. Chem. Soc. 1992, 114, 10672.

[28] Phillips, S. T.; Rezac, M.; Abel, U.; Kossenjans, M.; Bartlett, P. A. J. Am. Chem. Soc. 2002, 124, 58.

[29] Violette, A.; Averlant-Petit, M. C.; Semetey, V.; Hemmerlin, C.; Casimir, R.; Graff, R.; Marraud, M.; Briand, J. P.; Rognan, D.; Guichard, G. J. Am. Chem. Soc. 2005, 127, 2156.

[30] Angelo, N. G.; Arora, P. S. J. Org. Chem. 2007, 72, 7963.

[31] Alper, P. B.; Hung, S. C.; Wong, C. H. Tetrahedron Lett. 1996, 37, 6029.

[32] Nyffeler, P. T.; Liang, C. H.; Koeller, K. M.; Wong, C. H. J. Am. Chem. Soc. 2002, 124, 10773.

[33] Rostovtsev, V. V.; Green, L. G.; Fokin, V. V.; Sharpless, K. B. Angew. Chem., Int. Ed. 2002, 41, 2596.

[34] Tornoe, C. W.; Christensen, C.; Meldal, M. J. Org. Chem. 2002, 67, 3057.

[35] Barreto, A. de F. S.; Vercillo, O. E.; Birkett, M. A.; Caulfield, J. C.; Wessjohann, L. A.; Andrade, C. K. Z. Org. Biomol. Chem. 2011, 9, 5024.

[36] Cecioni, S.; Faure, S.; Darbost, U.; Bonnamour, I.; Parrot-Lopez, H.; Roy, O.; Taillefumier, C.; Wimmerova, M.; Praly, J.-P.; Imberty, A.; Vidal, S. Chem. Eur. J. 2011, 17, 2146.

[37] Perissutti, E.; Frecentese, F.; Fiorino, F.; Severino, B.; Cirillo, D.; Santagada, V.; Caliendo, G. J. Heterocycl. Chem. 2007, 44, 815.

[38] Van Dijk, M.; Mustafa, K.; Dechesne, A. C.; van Nostrum, C. F.; Hennink, W. E.; Rijkers, D. T. S.; Liskamp, R. M. J. Biomacromol. 2007, 8, 327.

[39] Van Dijk, M.; Nollet, M. L.; Weijers, P.; Dechesne, A. C.; van Nostrum, C. F.; Hennink, W. E.; Rijkers, D. T. S.; Liskamp, R. M. J. Biomacromolecules 2008, 9, 2834.

[40] Elgersma, R. C.; van Dijk, M.; Dechesne, A. C.; van Nostrum, C. F.; Hennink, W. E.; Rijkers, D. T. S.; Liskamp, R. M. J. Org. Biomol. Chem. 2009, 7, 4517.

[41] Rijkers, D. T. S.; van Esse, G. W.; Merkx, R.; Brouwer, A. J.; Jacobs, H. J. F.; Pieters, R. J.; Liskamp, R. M. J. Chem. Commun. 2005, 4581 .

[42] Rijkers, D. T. S.; van Esse, G. W.; Merkx, R.; Brouwer, A. J.; Jacobs, H. J. F.; Pieters, R. J.; Liskamp, R. M. J. Am. Peptide Soc. 2005, 152.

[43] Branderhorst, H. M.; Ruijtenbeek, R.; Liskamp, R. M. J.; Pieters, R. J. ChemBioChem 2008, 9, 1836.

[44] Dijkgraaf, I.; Rijnders, A. Y.; Soede, A.; Dechesne, A. C.; van Esse, G. W.; Brouwer, A. J.; Corstens, F. H. M.; Boerman, O. C.; Rijkers, D. T. S.; Liskamp, R. M. J. Org. Biomol. Chem. 2007, 5, 935.

[45] Kuil, J.; Branderhorst, H. M.; Pieters, R. J.; de Mol, N. J.; Liskamp, R. M. J. Org. Biomol. Chem. 2009, 7, 4088.

[46] van Ameijde, J.; Poot, A. J.; van Wandelen, L. T. M.; Wammes, A. E. M.; Ruijtenbeek, R.; Rijkers, D. T. S.; Liskamp, R. M. J. Org. Biomol. Chem. 2010, 8, 1629.

[47] Yoon, K.; Goyal, P.; Weck, M. Org. Lett. 2007, 9, 2051.

[48] Arnusch, C. J.; Branderhorst, H.; de Kruijff, B.; Liskamp, R. M. J.; Breukink, E.; Pieters, R. J. Biochemistry 2007, 46, 13437.

[49] Kaval, N.; Bisztray, K.; Dehaen, W.; Kappe, C. O.; Van der Eycken, E. Mol. Diversity 2003, 7, 125.

[50] De Borggraeve, W. M.; Rombouts, F. J. R.; Van der Eycken, E.; Toppet, S. M.; Hoornaet, G. T. Tetrahedron Lett. 2001, 42, 5693.

[51] Ermolat'ev, D.; Dehaen, W.; Van der Eycken, E. QSAR Comb. Sci. 2004, 23, 915

[52] Pietrzik, N.; Schmollinger, D.; Ziegler, T. Belstein J. Org. Chem. 2008, 4, 30
[53] Pietrzik, N.; Schips, C.; Ziegler, T. Synthesis 2008, 519.

[54] Miller, N.; Williams, G. M.; Brimble, M. A. Org. Lett. 2009, 11, 2409.

[55] Capicciotti, C. J.; Trant, J. F.; Leclere, M.; Ben, R. N. Bioconjugate Chem. 2011, 22, 605.

[56] Morvan, F.; Meyer, A.; Jochum, A.; Sabin, C.; Chevolot, Y.; Imberty, A.; Praly, J.; Vasseur, J.; Souteyrand, E.; Vidal S. Bioconjugate Chem. 2007, 18, 1637.

[57] Pourceau, F.; Meyer, A.; Vasseur, J. J.; Morvan, F. J. Org. Chem. 2008, 73, 6014 .

[58] Bouillon, C.; Meyer, A.; Vidal, S.; Jochum, A.; Chevolot, Y.; Cloarec, J.; Praly, J.; Vasseur, J.; Morvan, F. J. Org. Chem. 2006, 71,4700 .

[59] Bew, S. P.; Brimage, R. A.; L'Hermit, N.; Sharma, S. V. Org. Lett. $2007,9,3713$.

[60] El Seoud, O. A.; Koschella, A.; Fidale, L. C.; Dorn, S.; Heinze, T. Biomacromolecules 2007, 8, 2629.

[61] Parvulescu, V. I.; Hardacre, C. Chem. Rev. 2007, 107, 2615.

[62] Van Rantwijk, F.; Sheldon, R. A. Chem. Rev. 2007, 107, 2757.

[63] Weingartner, H. Angew. Chem., Int. Ed. 2008, 47, 654.

[64] Vecchi, A.; Melai, B.; Marra, A.; Chiappe, C.; Dondoni, A. J. Org. Chem. 2008, 73, 6437 .

[65] Cecioni, S.; Lalor, R.; Blanchard, B.; Praly, J.-P.; Imberty, A.; Matthews, S. E.; Vidal, S. Chem. Eur. J. 2009, 15, 13232.

[66] Garska, B.; Tabatabai, M.; Ritter, H. Beilstein J. Org. Chem. 2010, $6,784$.

[67] Consoli, G. M. L.; Granata, G.; Geraci, C. Org. Biomol. Chem. 2011, 9, 6491.

[68] Joosten, J. A. F.; Tholen, N. T. H.; El Maate, F. A.; Brouwer, A. J.; van Esse, G. W.; Rijkers, D. T. S.; Liskamp, R. M. J.; Pieters, R. J. Eur. J. Org. Chem. 2005, 3182.

[69] Pérez-Balderas, F.; Ortega-Munoz, M.; Morales-Sanfrutos, J.; Heràndez-Mateo, F.; Calvo-Flores, F. G.; Calvo-Asìn, J. A.; Isac-Garcìa, J.; Santoyo-Gonzàlez, F. Org. Lett. 2003, 5, 1951.

[70] Mallard-Favier, I.; Blach, P.; Cazier, F.; Delattre, F. Carbohydr. Res. 2009, 344, 161.

[71] Zhang, L. F.; Wong, Y. C.; Chen, L.; Ching, C. B.; Ng, S. C. Tetrahedron Lett. 1999, 40, 1815.

[72] Berscheid, R.; Nieger, M.; Votle, F. J. Chem. Soc., Chem. Commun. 1991, 19, 1364.

[73] Nithyanandhan, J.; Jayaraman, N. J. Org. Chem. 2002, 67, 6282.

[74] Cravotto, G.; Mendicuti, F.; Martina, K.; Tagliapietra, S.; Robaldo, B.; Barge, A. Synlett 2008, 2642.

[75] Aime, S.; Gianolio, E.; Arena, F.; Barge, A.; Martina, K.; Heropoulos, G.; Cravotto, G. Org. Biomol. Chem. 2009, 7, 370.

[76] Song, Y.; Kohlmeir, E. K.; Meade, T. J. J. Am. Chem. Soc. 2008, 130,6662 .

[77] Tran, D. N.; Blaszkiewicz, C.; Menuel,S.; Roucoux, A.; Philippot, K.; Hapiot ,F.; Monflier E. Carbohydr. Res. 2011, 346, 210.

[78] Hoogenboom, R.; Moore, B. C.; Schubert, U. S. Chem. Commun. 2006, 4010.

[79] Fijten, M. W. M.; Haensch, C.; van Lankvelt, B. M.; Hoogenboom, R.; Schubert, U. S. Macromol. Chem. Phys. 2008, 209, 1887.

[80] Ortega-Munoz, M.; Morales-Sanfrutos, Julia.; Perez-Balderas, F.; Hernandez-Mateo, F. Org. Biomol. Chem. 2007, 5, 2291.

[81] Kishi, K.; Ishimaru, T.; Ozono, M.; Tomita, I.; Endo, T. J. Polym. Sci. Part A: Polym. Chem. 2000, 38, 35.

[82] Ashton, P. R.; Koeniger, R.; Stoddart, J. F.; Alker, D.; Harding, V. D. J. Org. Chem. 1996, 61, 903.

[83] Munteanu, M.; Choi, S.; Ritter, H. J. Inclusion Phenom. Macrocyclic Chem. 2008, 62, 197.

[84] Munteanu, M.; Choi, S. W.; Ritter, H. Macromolecules 2008, 41, 
9619.

[85] Maeda, C.; Yamaguchi, S.; Ikeda, C.; Shinokubo, H.; Osaka, A. Org. Lett. 2008, 10, 549.

[86] Elmer, S. L.; Man, S.; Zimmerman, S. C. Eur. J. Org. Chem. 2008, 3845.

[87] Hirohara, S.; Obata, M.; Alitomo, H.; Sharyo, K.; Ogata, S.; Ohtsuki, C.; Yano, S.; Ando, T.; Tanihara, M. Biol. Pharm. Bull. 2008, $31,2265$.

[88] Laville, I.; Pigaglio, S.; Blais, J. C.; Doz, F.; Loock, B.; Maillard, P.; Grierson, D. S.; Blais, J. J. Med. Chem. 2006, 49, 2558.

[89] Tomé, J. P. C.; Neves, M. G. P. M. S.; Tomé, A. C.; Calaleiro, J. A. S.; Mendonça, A. F.; Pegado, I. N.; Duarte, R.; Valdeira, M. L. Bioorg. Med. Chem. 2005, 13, 3878.

[90] Sylvain, I.; Zerrouki, R.; Granet, R.; Huang, Y. M.; Lagorce, J. F. Guilloton, M.; Blais, J. C.; Krausz, P. Bioorg. Med. Chem. 2002, $10,57$.

[91] Dalvie, D. K.; Kalgutkar, A. S.; Khojasteh-Bakht, S. C.; Obach, R. S.; O'Donnell, J. P. Chem. Res. Toxicol. 2002, 15, 269.

[92] Di Stasio, B.; Frochot, C.; Dumas, D.; Even, P.; Zwier, J.; Müller, A.; Didelon, J.; Guillemin, F.; Viriot, M.-L.; Barberi-Heyob, M. Eur. J. Med. Chem. 2005, 40, 1111.

[93] Locos, O. B.; Heindl, C. C.; Corral, A.; Senge, M. O.; Scanlan, E. M. Eur. J. Org. Chem. 2010, 1026.

[94] Garcia, G.; Naud-Martin, D.; Carrez, D.; Croisy, A.; Maillard, P. Tetrahedron 2011, 67, 4924.

[95] Bakleh, M. E.; Sol, V.; Estieu-Gionnet, K.; Granet, R.; Deleris, G.; Krausz, P. Tetrahedron 2009, 65, 7385.

[96] Luo, C.; Guldi, D. M.; Imahori, H.; Tamaki, K.; Sakata, Y. J. Am. Chem. Soc. 2000, 122, 6535.

[97] Meijer, M. D.; Van Klink, G. P. M.; Van Koten, G. Coord. Chem. Rev. 2002, 230, 141.

[98] Fazio, M. A.; Lee, O. P. Schuster, D. I. Org. Lett. 2008, 10, 4979.

[99] Isobe, H.; Cho, K.; Solin, N.; Werz, D. B.; Seeberger, P. H.; Nakamura, E. Org. Lett. 2007, 9, 4611.

[100] Sawamura, M.; Iikura, H.; Nakamura, E. J. Am. Chem. Soc. 1996, 118,12850 .

[101] Nakamura, E. J. Organomet. Chem. 2004, 689, 4630.

[102] Cheshev, P.; Marra, A.; Dondoni, A. Org. Biomol. Chem. 2006, 4, 3225 .

[103] Isobe, H.; Fujino, T.; Yamazaki, N.; Guillot-Nieckowski, M.; Nakamura, E. Org. Lett. 2008, 10, 3729.

[104] Lietard, J.; Meyer, A.; Vasseur, A.; Morvan, F. J. Org. Chem. 2008, $73,191$.

[105] Meyer, A.; Pourceau, G.; Vasseur, J.-J.; Morvan, F. J. Org. Chem. 2010, 75, 6689.

[106] Nothisen, M.; Kotera, M.; Voirin, E.; Remy, J.-S.; Behr, J.-P. J. Am. Chem. Soc. 2009, 131, 17730.

[107] Konate, K.; Crombez, L.; Deshayes, S.; Decaffmeyer, M.; Thomas, A.; Brasseur, R.; Aldrian, G.; Heitz, F.; Divita, G. Biochemistry 2010, 49, 3393.

[108] Manoharan, M. Antisense Nucleic Acid Drug Dev. 2002, 12, 103.

[109] Yamada, T.; Peng, C. G.; Matsuda, S.; Addepalli, H.; Jayaprakash, K. N.; Alam, M. R.; Mills, K.; Maier, M. A.; Charisse, K.; Sekine, M.; Manoharan, M.; Rajeev, K. G. J. Org. Chem. 2011, 76, 1198.

[110] Chaubey, B.; Tripathi, S.; Desire, J.; Baussanne, I.; Décout, J.-L.; Pandey, V. N. Oligonucleotides 2007, 17, 302.

[111] Ketomäki, K.; Virta, P. Bioconjugate Chem. 2008, 19, 766.

[112] Alguacil, J.; Defaus, S.; Claudio, A.; Trapote, A.; Masides, M.; Robles. J. Eur. J. Org. Chem. 2010, 3102.

[113] Sreedhara, J.; Cowan, A. J. Biol. Inorg. Chem. 2001, 6, 166.

[114] Kalish, J. M.; Glazer, P. M. Ann. N. Y. Acad. Sci. 2005, 1058, 151.

[115] Géci, I.; Filichev, V. V.; Pedersen, E. B. Chem. Eur. J. 2007, 13,
6379.

[116] Krim, J.; Sillahi, B.; Taourirte, M.; Rakib, E. M.; Engels, J. W. ARKIVOC 2009, XIII, 142.

[117] Pradere, U.; Roy, V.; Mc Brayer, T.; Schinazi, R. F.; Agrofoglio, L. A. Tetrahedron 2008, 64, 9044.

[118] Lau, J. Y.; Tam, R. C.; Liang, T. J.; Hong, Z. Hepatology 2002, 35, 1002.

[119] Rasmussen, L. K.; Boren, B. C.; Fokin, V. V. Org. Lett. 2007, 9, 5337.

[120] Zhang, L.; Chen, X. G.; Xue, P.; Sun, H. H. Y.; Williams, I. D.; Sharpless, K. B.; Fokin, V. V.; Jia, G. J. Am. Chem. Soc. 2005, 127, 15998.

[121] El Akri, K.; Bougrin, K.; Balzarini, J.; Faraj, A.; Benhida, R. Biorg. Med. Chem. Lett. 2007, 17, 6656.

[122] Guezguez, R.; Bougrin, K.; El Akri, K.; Benhida, R. Tetrahedron Lett. 2006, 47, 4807.

[123] Modha, S. G.; Trivedi, J. C.; Mehta, V. P.; Ermolat'ev, D. S.; Van der Eycken, E. J. Org. Chem. 2011, 76, 846.

[124] Ermolat'ev, D. S.; Mehta, V. P.; Van der Eycken, E. QSAR Comb. Sci. 2007, 26, 1266.

[125] Broggi, J.; Joubert, N.; Aucagne, V.; Berteina-Raboin, S.; Diez-Gonzales, S.; Nolan, S.; Topalis, D.; Deville-Bonne, D.; Balzarini, J.; Netyts, J.; Andrei, G.; Snoeck, R.; Agrofoglio, L. A. Nucleosides Nucleotides Nucleic Acids 2007, 26, 1391.

[126] Broggi, J.; Joubert, N.; Aucagne, V.; Zevaco, T.; Berteina-Raboin, S.; Nolan, S. P.; Agrofolio, L. A. Nucleosides Nucleotides Nucleic Acids 2007, 26, 779.

[127] Broggi, J.; Kumamoto, H.; Berteina-Raboin, S.; Nolan, S. P.; Agrofoglio, L. A. Eur. J. Org. Chem. 2009, 1880.

[128] Lucas, R.; Neto, V.; Bouazza, A. H.; Zerrouki, R.; Granet, R.; Krausz, P.; Champavier, Y. Tetrahedron Lett. 2008, 49, 1004.

[129] Lucas, R.; Zerrouki, R.; Granet, R.; Krausz, P.; Champavier, Y. Tetrahedron 2008, 64, 5467.

[130] Lin, J.; Roy, V.; Wang, L.; You, L.; Agrofoglio, L. A.; DevilleBonne, D.; McBrayer, T. R.; Coats, S. J.; Schinazi, R. F.; Eriksson, S. Bioorg. Med. Chem. 2010, 18, 3261.

[131] Montagu, A.; Roy, V.; Balzarini, J.; Snoeck, R.; Andrei, G.; Agrofoglio, L. A. Eur. J. Med. Chem. 2011, 46, 778.

[132] Savin, K. A.; Robertson, M.; Gernert, D.; Green, S.; Hembre, E. J.; Bishop, J. Mol. Diversity 2003, 7, 171.

[133] Appukkuttan, P.; Dehaen, W.; Fokin, V. V.; Van der Eycken, E. Org. Lett. 2004, 6, 4223.

[134] Johansson, J. R.; Lincoln, P.; Noren, B.; Kann, N. J. Org. Chem. 2011, 76, 2355.

[135] Moorhouse, A. D.; Moses, J. E. Synlett 2008, 2089.

[136] Beckmann, H. S. G.; Wittmann, V. Org. Lett. 2007, 9, 1.

[137] Akubathini, S. K.; Biehl, E. Tetrahedron Lett. 2009, 50, 1809.

[138] Shi, F.; Waldo, J. P.; Chen, Y.; Larock, R. C. Org. Lett. 2008, 10, 2409.

[139] Yang, D.; Kwon, M.; Jang, Y.; Jeon, H. B. Tetrahedron Lett. 2010, $51,3691$.

[140] Katritzky, A. R.; Singh, S. K. J. Org. Chem. 2002, 67, 9077.

[141] Katritzky, A. R.; Zhang, Y.; Singh, S. K.; Steel, P. J. ARKIVOC 2003, $X V, 47$.

[142] Louerat, F.; Bougrin, K.; Loupy, A.; Ochoa de Retana, A. M.; Pagalday, J.; Palacios, F. Heterocycles 1998, 48, 161.

[143] Wang, J.; He, X.; Gao, L.; Sheng, L.; Shi, X.; Li, J.; Chen, G. Chin. J. Chem. 2011, 29, 1227.

[144] Liu, S.; Zeng, L.-F.; Wu, L.; Yu, X.; Xue, T.; Gunawan, A. M.; Long, Y.-Q.; Zhang, Z.-Y. J. Am. Chem. Soc. 2008, 130, 17075.

[145] Yang, J. W.; He, X. P.; Li, C.; Gao, L. X.; Sheng, L.; Xie, J.; Shi, X. X.; Tang, Y.; Li, J.; Chen, G. R. Bioorg. Med. Chem. Lett. 2011, 


\section{1, 1092.}

[146] He, X. P.; Li, C.; Jin, X. P.; Song, Z.; Zhang, H. L.; Zhu, C. J.; Shen, Q.; Zhang, W.; Sheng, L.; Shi, X. X.; Tang, Y.; Li, J.; Chen, G. R.; Xie, J. New J. Chem. 2011, 35, 622.

[147] Yang, J. W.; Li, C.; He, X. P.; Zhao, H.; Gao, L. X.; Zhang, W.; Shi, X. X.; Tang, Y.; Li, J.; Chen, G. R. Bull. Korean Chem. Soc. 2010, 31, 3359.

[148] He, X.-P.; Song, Z.; Wang, Z.-Z.; Shi, X.-X.; Chen, K.-X.; Chen, G.-R. Tetrahedron 2011, 67, 3343.

[149] Kosiova, I.; Kovackova, S.; Kois, P. Tetrahedron 2007, 63, 312.

[150] Glasnov, T. N.; Kappe, C. O. QSAR Comb. Sci. 2007, 26, 1261.

[151] Mayot, E.; Gerardin-Charbonnier, C.; Selve, C. J. Fluorine Chem. 2005, 126, 715 .

[152] Song, S.-X.; Zhang, H.-L.; Kim, C.-G.; Sheng, L.; He, X.-P.; Long, Y.-T.; Li, J.; Chen, G.-R. Tetrahedron 2010, 66, 9974.

[153] Castagnolo, D.; Dessì, F.; Radi, M.; Botta, M. Tetrahedron: Asymmetry 2008, 18, 1345.

[154] Beryozkina, T.; Appukkuttan, P.; Mont, N.; Van der Eycken, E. Org. Lett. 2006, 8, 487.
[155] Mont, N.; Metha, V. P.; Appukkuttan, P.; Beryozkina, T.; Toppet, S.; Van Hecke, K.; Van Meervelt, L.; Voet, A.; DeMaeyer, M.; Van der Eycken, E. J. Org. Chem. 2008, 73, 7509.

[156] Donets, P. A.; Van der Eycken, E. V. QSAR Comb. Sci. 2007, 26, 1239.

[157] Kaval, N.; Ermolat'ev, D.; Appukkuttan, P.; Dehaen, W.; Kappe, O.; Van derEycken, E. J. Comb. Chem. 2005, 7, 490.

[158] Dedola, S.; Hughes, D. L.; Nepogodiev, S. A.; Rejzek, M.; Field, R. A. Carbohydr. Res. 2010, 345, 1123.

[159] Zhang, W. S.; Su, C. H.; Jiang, Y. B.; Kuang, C. X. Res. Chem. Intermed. 2009, 35, 589.

[160] Cintas, P.; Martina, K.; Robaldo, B.; Garella, A.; Boffa, L.; Cravotto, G. Collect. Czech. Chem. Commun. 2007, 72, 1014.

[161] Cravotto, G.; Cintas, P. Chem. Eur. J. 2007, 13, 1902.

[162] Lipshutz, B. H.; Taft, B. R. Angew. Chem., Int. Ed. 2006, 45, 8235.

[163] Kang, H.; Lee, H. J.; Park, J. C.; Song, H.; Park, K. H. Top. Catal. 2010, 53, 523 .

[164] Alonso, F.; Moglie, Y.; Radivoy, G.; Yus, M. Eur. J. Org. Chem. 2010, 1875.

(Cheng, F.) 